\title{
Effect of Cation Enrichment on Dipalmitoylphosphatidylcholine (DPPC) Monolayers at the Air-Water Interface
}

\author{
Ellen M. Adams, Clayton B. Casper ${ }^{\dagger}$, and Heather C. Allen*
}

The Ohio State University, Department of Chemistry and Biochemistry, 100 West 18th

Avenue, Columbus, OH 43210, USA

Tel: +1-614-292-4772; Fax: +1-614-292-1685; 


\begin{abstract}
The effect of highly concentrated salt solutions of marine-relevant cations $\left(\mathrm{Na}^{+}, \mathrm{K}^{+}\right.$, $\mathrm{Mg}^{2+}$, and $\mathrm{Ca}^{2+}$ ) on Langmuir monolayers of dipalmitoylphosphatidylcholine (DPPC) was investigated by means of surface pressure-area isotherms, Brewster angle microscopy (BAM), and infrared reflection-absorption spectroscopy (IRRAS). It was found that monovalent cations and $\mathrm{Mg}^{2+}$ have similar phase behavior, causing DPPC monolayers to expand, while $\mathrm{Ca}^{2+}$ induces condensation. All cations disrupted the surface morphology at high cation concentration, resulting in decreased reflectivity from the monolayer. Monolayer refractive index was calculated from BAM image intensity in the liquid condensed phase and decreased with increasing cation concentration, which suggests that orientation of the alkyl chains change. Monovalent ions increase ordering of the alkyl chains, more than divalents, yet have little interaction with the DPPC headgroup. $\mathrm{Mg}^{2+}$ induces gauche defects in the alkyl chain and increases headgroup hydration at low lipid coverage but increases chain ordering and dehydrates the headgroup at high lipid coverage. $\mathrm{Ca}^{2+}$ orders alkyl chains and dehydrates the phosphate moiety, independent of lipid phase. At the highest salt concentration investigated, significant narrowing of the asymmetric $\mathrm{PO}_{2}^{-}$vibrational mode occurs and is attributed to considerable dehydration of the DPPC headgroup.
\end{abstract}

Keywords: Dipalmitoylphosphatidylcholine (DPPC), monolayers, cations, marine aerosols, Langmuir isotherms, Brewster angle microscopy (BAM), Infrared reflectionabsorption spectroscopy (IRRAS) 


\section{Introduction}

Sea spray aerosols (SSA) produced from wave breaking are known to impact climate [1]. Yet, their influence on radiative forcing, whether directly through light scattering and absorption [2] or, indirectly, by their ability to act as cloud condensation nuclei [3] and ice nucleating particles [4], remains uncertain. The impact of SSA on climate depends on their chemical composition [1], as this dictates their chemical and physical properties $[3,5,6]$. SSA are commonly complex mixtures of salts and organic species. Moreover, organic content and composition vary widely as they are driven by biological activity at the ocean surface [7-10].

Recent studies of nascent sea spray generated during the course of a phytoplankton bloom found that four distinct particle types are produced [6,11]. Two of these particles types, organic carbon (OC) and sea-salt organic carbon (SSOC), have been characterized in terms of their chemical composition $[12,13]$. OC particles are composed of insoluble organic species and inorganic ions such as sulfate $\left(\mathrm{SO}_{4}{ }^{2-}\right)$, sodium $\left(\mathrm{Na}^{+}\right)$, magnesium $\left(\mathrm{Mg}^{2+}\right)$, calcium $\left(\mathrm{Ca}^{2+}\right)$, and potassium $\left(\mathrm{K}^{+}\right)$. Notably, these particles lack a signature from chlorine $\left(\mathrm{Cl}^{-}\right)$[12]. The organic species in $\mathrm{OC}$ particles are thought to be aliphatic-rich lipids, likely phospholipids, which constitute a major class of lipids produced by phytoplankton [13]. Dried SSOC particles have a sea-salt core, mostly composed of $\mathrm{NaCl}$, covered by an organic coating. Aerosol time-of-flight mass spectrometry (ATOFMS) and scanning transmission X-ray microscopy with near edge Xray absorption fine structure (STXM-NEXAFS) measurements suggest that oxidized-rich species, such as fatty acids, make up a large fraction of the organic material in these particles [12,13]. Despite differences in composition, an enrichment of divalent ions 
occurs in both types of particles. $\mathrm{Ca}^{2+}$ is observed in OC particles [11], whereas $\mathrm{Mg}^{2+}$ and $\mathrm{Ca}^{2+}$ are both enhanced in SSOC particles; however, $\mathrm{Mg}^{2+}$ is much more prevalent [12]. Furthermore, in the case of the SSOC particles, the enrichment of these divalent ions as well as $\mathrm{K}^{+}$occurs at the interface of the particles $[12,14]$, suggesting that these ions are coordinated to surface-active organics.

Complexation of ions to surface-active species, such as lipids, is known to alter their orientation [15], packing [16,17], and surface morphology [18]. Interfacial properties of organic films impact the chemical and optical properties of aerosols including albedo [19], hygroscopicity [20], and reactivity [21]. For example, it was shown that light scattering of organic-coated $\mathrm{NaCl}$ particles decreases as the volume fraction of organics increases [19]. To date, many studies of organic-coated aerosols have relied on dried salt cores selectively coated with an organic surfactant as model systems [19-21]. While valuable at providing insight into aerosol chemistry, these models lack some representative properties of aqueous aerosols generated from the ocean surface (although drying of the aerosol will occur in the atmosphere). Furthermore, most of these studies have used $\mathrm{NaCl}$ as the main inorganic salt, thus neglecting the importance of other marine-relevant ions such as alkaline earth cations $\left(\mathrm{Ca}^{2+}, \mathrm{Mg}^{2+}\right)$. Therefore, in order to fully grasp the impact that ions have on marine aerosol properties, a fundamental understanding of how ion enrichment in a hydrated environment, especially enrichment of divalent ions, influences the surface properties of the organic coating is needed.

In this work, Langmuir monolayers of lipids spread on marine-relevant salt solutions in various concentration regimes are used as a model system to determine how monovalent and divalent cations alter the interfacial properties of organic-coated marine 
aerosols as they are entrained in the atmosphere. Dipalmitoylphosphatidylcholine (DPPC) was chosen as a representative lipid as it has been well studied [22-24], and is known to be enriched in the sea surface microlayer (SSML) $[25,26]$, and therefore likely found in marine aerosols. Aqueous solutions consisting of monovalent $\left(\mathrm{Na}^{+}, \mathrm{K}^{+}\right)$and divalent $\left(\mathrm{Mg}^{2+}, \mathrm{Ca}^{2+}\right)$ chloride salts were used to represent the aerosol aqueous salt core. Typical concentrations of these cations in seawater are $0.45 \mathrm{M}\left(\mathrm{Na}^{+}\right), 0.01 \mathrm{M}\left(\mathrm{K}^{+}\right), 0.05 \mathrm{M}$ $\left(\mathrm{Mg}^{2+}\right)$, and $0.01 \mathrm{M}\left(\mathrm{Ca}^{2+}\right)$, respectively [27]. Here, the salt concentrations were varied from 0.3 to $2.0 \mathrm{M}$ to represent different stages of marine aerosol evaporation and different degrees of ion enrichment at the interface. Similar $\mathrm{Cl}^{-}$concentrations were used to directly compare effects due to cation identity. To determine the influence of cation identity and concentration on the interfacial phase behavior of the DPPC monolayer surface pressure-area isotherms were measured on the various salt solutions. In addition, Brewster angle microscopy images were collected to assess the impact of cation enrichment on the surface morphology and refractive index of the DPPC monolayer. Infrared reflection-absorption spectroscopy was used to determine potential cation effects on the conformational order of lipid alkyl chains and the extent of cation interaction with the phosphatidylcholine (PC) headgroup. Results reported here indicate that the surface properties of the lipid film are altered in the presence of highly concentrated ions, and that these alterations have impacts on the optical properties of marine aerosols, specifically the refractive index.

\section{Experimental}

\subsection{Materials}


1,2-Dipalmitoyl-sn-glycero-3-phosphocholine (DPPC) (> 99\%, Avanti Polar Lipids) was used as received and dissolved in chloroform (HPLC grade, Fisher Scientific) to make a $1 \mathrm{mM}$ solution. Sodium chloride $(\mathrm{NaCl})(\geq 99 \%$, ACS certified, Fisher Scientific), potassium chloride (KCl) ( $\geq 99 \%$, ACS certified, Fisher Scientific), calcium chloride dihydrate $\left(\mathrm{CaCl}_{2} \bullet 2 \mathrm{H}_{2} \mathrm{O}\right)(\geq 99 \%$, FCC grade, Fisher Scientific), and magnesium chloride hexahydrate $\left(\mathrm{MgCl}_{2} \bullet 6 \mathrm{H}_{2} \mathrm{O}\right)(\geq 99 \%$, ACS certified, Fisher Scientific) were dissolved in water with a resistivity of $18.2 \mathrm{M} \Omega \cdot \mathrm{cm}$ and a measured $\mathrm{pH}$ of 5.6 (NANOpure Analytical Deionization System, model D4741, Barnstead/Thermolyne Corporation) to prepare stock solutions. These solutions were subsequently purified by a method that has been previously described [28]. Briefly, trace organic and inorganic impurities were removed by several filtrations through activated carbon filters (Whatman Carbon-Cap 75, Fisher Scientific). Cleanliness of the stock salt solutions was confirmed by the absence of spectral features in vibrational sum frequency generation (VSFG) spectra measured in the CH stretching region $\left(2800-3000 \mathrm{~cm}^{-1}\right)$. Concentration of the stock salt solutions was determined by Mohr's chloride titration method [29]. Solutions of desired concentration were then prepared by dilution of the stock salt solutions. All prepared solutions had a final $\mathrm{pH}$ in the range of 5-7 and were sealed from the ambient environment. Equilibration to ambient temperature $\left(23 \pm 1{ }^{\circ} \mathrm{C}\right)$ for a period of at least $12 \mathrm{~h}$ was allowed before measurements were performed.

\subsection{Methods}

\subsubsection{Surface pressure-area isotherms}


Surface pressure-molecular area $(\Pi-A)$ compression isotherms were measured on a computer-controlled Langmuir trough (Minitrough, KSV Instruments, Finland; $A_{\text {total }}=$ $144 \mathrm{~cm}^{2}$ ) made of Teflon and equipped with two compression barriers. Surface pressure of the monolayer was monitored with a Wilhelmy plate made of filter paper (Ashland grade, Whatman). Prior to measurements the trough and barriers were thoroughly rinsed with ethanol and nanopure water. Cleanliness of the aqueous surface was ensured by sweeping the barriers across the surface, where an aqueous surface was considered clean when $\Pi \leq 0.2 \mathrm{mN} / \mathrm{m}$. Monolayers were formed by spreading dropwise an appropriate volume of the lipid solution on the aqueous surface using a microsyringe (Hamilton). Ten minutes were allowed to pass for evaporation of the spreading solvent before compression. Monolayers were compressed at a constant rate of $5 \mathrm{~mm} / \mathrm{min} / \mathrm{barrier}$ up to the compression limit of $55 \mathrm{mN} / \mathrm{m}$, prior to collapse. Film leakage tends to occur at high surface pressures due to menisucus inversion of the solution surface [30], which makes reaching the collapse pressure of the DPPC monolayer $(72 \mathrm{mN} / \mathrm{m})$ difficult. Experiments were stopped at $55 \mathrm{mN} / \mathrm{m}$ to avoid film leakage. Isotherms were repeated at least three times to ensure reproducibility (see for example Fig. S1 in Supplementary Material). Standard deviations of the molecular area and surface pressure were $\pm 1 \AA^{2} /$ molecule and $\pm 0.5 \mathrm{mN} / \mathrm{m}$, respectively.

\subsubsection{Brewster angle microscopy (BAM)}

Surface morphology of the DPPC monolayers was assessed using a custom-built BAM setup that has been previously described [18,31]. Briefly, the $p$-polarized output of a $5 \mathrm{~mW}$ HeNe laser source (Research Electro-Optics; $\lambda=543 \mathrm{~nm}$ ) is reflected from the 
aqueous surface (either bare or lipid-covered) and collected by an infinity-corrected super-long working distance $10 \times$ objective lens (Nikon). A tube lens collimates the collected light before being recorded by a back-illuminated electron-multiplying chargecoupled device (EM-CCD) camera (DV887-BV, Andor Technology). A blue background was selected to enhance image contrast. Images were collected simultaneously with the compression isotherms in which an image was recorded every $4.85 \mathrm{~s}$ to make a movie. Still frames were then extracted from the movie at appropriate surface pressures or mean molecular areas. Because the inclined position of the collection optics causes images to be focused only over a narrow region of the visual field, all images were cropped from the full $800 \mu \mathrm{m} \times 800 \mu \mathrm{m}$ size to the most resolved region. Reproducibility of the BAM images is illustrated in Fig. S2 (Supplementary Material). Differences in the reflectivity of each solution were accounted for by adjusting the Brewster angle $\left(\theta_{B}=\tan ^{-1}\left(n_{s} / n_{a}\right)\right.$ where $n_{a}$ and $n_{s}$ are the refractive indices of air and aqueous solutions, respectively) such that each solution had a background gray level of 30 or less. The measured Brewster angle of each aqueous solution and the corresponding refractive index determined from the Brewster angle equation are listed in Table S1 (Supplementary Material). Calculated refractive indices are in good agreement with literature [32].

Refractive index of the monolayer $\left(n_{m}\right)$ on various solutions was calculated from BAM images using the following relation [33]:

$$
d=\frac{\lambda \sqrt{R_{p}}}{\pi \sin \left(2 \theta_{B}-90\right)} \frac{n_{m}^{2}\left(n_{a}^{2}-n_{s}^{2}\right)}{\sqrt{n_{a}^{2}+n_{s}^{2}}\left(n_{a}^{2}-n_{m}^{2}\right)\left(n_{s}^{2}-n_{m}^{2}\right)}
$$


where $d$ is the monolayer thickness, $\lambda$ is the laser wavelength, and $R_{p}$ is the measured reflectivity of $p$-polarized light from the surface. As $d$ and $n_{m}$ change concurrently, they cannot both be solved for using Equation 1. For simplicity, it was assumed that $d$ remains constant in the liquid condensed phase with a value of $2.48 \mathrm{~nm}$, as determined from previous BAM experiments [34]. Reflectivity values were related to the gray levels of the camera with calibrations curves as has been previously described [35,36]. Gray levels were averaged for horizontal lines at three separate pixels to determine an overall average gray level for each cropped BAM image. The gray level was then transformed to a reflectivity value based on the calibration curves.

\subsubsection{Infrared reflection-absorption spectroscopy (IRRAS)}

IRRAS spectra were collected using a custom-built setup placed in the chamber of a FTIR spectrometer (Spectrum 100, Perkin Elmer). The setup consisted of a small breadboard onto which the Langmuir minitrough was set. Two planar gold mirrors (2" diameter) were mounted on each side of the trough to direct and collect light from the aqueous surface. The incident mirror was positioned before the J-Stop Image distance (i.e., the set focus point of the incoming IR beam in the FTIR chamber) so that the incident beam was most focused at the aqueous surface. An incident angle of $46^{\circ}$ from the surface normal was used here. The barriers of the trough were either held at a constant mean molecular area (MMA) or allowed to oscillate to maintain a fixed surface pressure during measurements. All spectra were obtained with a $\mathrm{HgCdTe}$ (MCT) detector as a single beam measurement, with a single beam measurement of the respective bare aqueous surface used as the background spectrum. Spectra covered a range from 400 to 
$4000 \mathrm{~cm}^{-1}$ and were averaged over 300 scans with a resolution of $4 \mathrm{~cm}^{-1}$. Measurements were repeated at least three times to ensure reproducibility. Post-processing of spectra was done in OriginPro 9.0 (OriginLab), where baseline correction was done by fitting a third-order polynomial in the region of interest. Final spectra shown here are an average of at least three baseline-corrected spectra.

\section{Results and Discussion}

\subsection{Cation identity and salt concentration effects on the phase behavior and stability of}

\section{DPPC monolayers}

$\Pi-A$ compression isotherms of DPPC monolayers on different chloride salt solutions $\left(\mathrm{NaCl}, \mathrm{KCl}, \mathrm{MgCl}_{2}\right.$, and $\left.\mathrm{CaCl}_{2}\right)$ with varying concentrations are shown in Fig. 1. An isotherm of DPPC on water is also given for reference. The phase behavior of DPPC on water has been well documented [37]. With decreasing MMA (and at ambient temperature), the DPPC isotherm typically exhibits the following phases: gaseous $(\mathrm{G})$, liquid-expanded (LE), LE-liquid-condensed (LC) coexistence phase seen in the form of a plateau region, and LC.

All phases described above are also present for DPPC monolayers on $\mathrm{NaCl}$ solutions (Fig. 1a). Relative to water, an increase in MMA occurs in the low surface pressure regime for $0.6 \mathrm{M} \mathrm{NaCl}$. As the monolayer is compressed to higher surface pressures (> $35 \mathrm{mN} / \mathrm{m})$, DPPC molecules occupy the same MMA as on water, suggesting that excess $\mathrm{Na}^{+}$ions are squeezed out of the monolayer. A total expansion of the monolayer occurs on the $2.0 \mathrm{M} \mathrm{NaCl}$ solution, where a larger MMA relative to water occurs at all surface pressures. The phase behavior of DPPC on $\mathrm{NaCl}$ solutions has been 
studied extensively, and a shift to higher MMAs in the LE and LE-LC coexistence phases has also been previously observed for moderately concentrated $(\geq 0.1 \mathrm{M})$ solutions [15,38-43]. The extent of the MMA shift seems concentration-dependent, as it increases by 3-6 $\AA^{2} /$ molecule for concentrated solutions ( $\geq 0.5 \mathrm{M}$ ) [15,40,41], and is shifted 1-2 $\AA^{2} /$ molecule for $0.1 \mathrm{M}$ solutions $[38,39]$.

Similar to the $\mathrm{NaCl}$ series, 0.6 and $2.0 \mathrm{M} \mathrm{KCl}$ solutions cause the DPPC monolayer to occupy a larger MMA compared to water (Fig. 1b). Also like $\mathrm{Na}^{+}, \mathrm{K}^{+}$ions are squeezed out of the monolayer at high surface pressures (> $25 \mathrm{mN} / \mathrm{m}$ ) for $0.6 \mathrm{M} \mathrm{KCl}$, but cause an expansion at all surface pressures on $2.0 \mathrm{M} \mathrm{KCl}$. The impact of $\mathrm{K}^{+}$on the phase behavior of DPPC, or any other saturated PCs in general, has been less studied than $\mathrm{Na}^{+}[44,45]$, but previous reports are consistent with results presented here, where expansion of the monolayer occurs in the presence of $\mathrm{K}^{+}$.

In the case of $0.6 \mathrm{M}$ solutions, $\mathrm{K}^{+}$has a smaller change in area ( $\Delta \mathrm{A}$, relative to water) than $\mathrm{Na}^{+}$in the LC phase (Fig. 2a), which may indicate that $\mathrm{K}^{+}$ions do not interact as strongly with the DPPC headgroup as $\mathrm{Na}^{+}$ions. MD simulations support this, with many suggesting that at low concentrations $(\sim 0.2 \mathrm{M}) \mathrm{K}^{+}$only weakly interacts, if at all, with PC headgroups, while $\mathrm{Na}^{+}$strongly interacts [46,47]. Equilibria calculations, however, find that PC- $\mathrm{K}^{+}$complexes are more stable than $\mathrm{PC}-\mathrm{Na}^{+}$complexes [48]. No definitive conclusion on relative binding affinity of $\mathrm{Na}^{+}$vs. $\mathrm{K}^{+}$to DPPC can be made from $\Pi$-Area isotherms presented here as contrary $\Delta \mathrm{A}$ values are observed between 0.6 and 2.0 M solutions. $\mathrm{K}^{+}$has a larger $\Delta \mathrm{A}$ than $\mathrm{Na}^{+}$for $2.0 \mathrm{M}$ solutions and is likely not indicative of increased PC- $\mathrm{K}^{+}$interactions, but rather the presence of excess unbound $\mathrm{K}^{+}$ ions in the interfacial region which cause increased electrostatic repulsions, and force 
DPPC molecules to be further apart. Comparison of $\Delta \mathrm{A}$ for $2.0 \mathrm{M} \mathrm{NaCl}$ and $\mathrm{KCl}$ solutions at several different surface pressures (Fig. 2b) shows similar $\Delta \mathrm{A}$ values for the two cations. Results shown here indicate that at high concentrations monovalent cations $\mathrm{Na}^{+}$and $\mathrm{K}^{+}$interact similarly with DPPC molecules, where expansion of the monolayer is likely due to increased electrostatic repulsions in the interfacial region.

The impact of divalent cations on the phase behavior of the DPPC monolayer depends on the identity of the cation. For instance, $\mathrm{Mg}^{2+}$ has a similar effect to monovalent ions, in which $\mathrm{MgCl}_{2}$ solutions result in DPPC molecules occupying a larger MMA relative to water. Expansion becomes more evident with increasing concentration (Fig. 1c), also similar to monovalent ions. In the case of $0.3 \mathrm{M} \mathrm{MgCl}_{2}$, the isotherm largely overlaps with that of water with deviations occurring in the LC phase, in which a smaller MMA is observed (Fig. 2a). For $1.0 \mathrm{M} \mathrm{MgCl}_{2}$ a larger MMA occurs in all phases except LC (> $40 \mathrm{mN} / \mathrm{m}$ ), which overlaps with the DPPC isotherm on water. This indicates that for 0.3 and $1.0 \mathrm{M}$ solutions $\mathrm{Mg}^{2+}$ ions are likely being squeezed out of the monolayer at high surface pressures. The isotherm of DPPC on $2.0 \mathrm{M} \mathrm{MgCl}_{2}$ is expanded at all MMAs. In contrast, previous studies have found that expansion of PC monolayers also occur at all MMAs in the presence of $\mathrm{Mg}^{2+}[49,50]$. These studies, however, used significantly lower concentrations $(<50 \mathrm{mM})$ of $\mathrm{MgCl}_{2}$ or PCs with different chain lengths and degree of saturation, which makes direct comparison to results here difficult. In any case, the similarity in DPPC phase behavior on $\mathrm{MgCl}_{2}$ compared to $\mathrm{NaCl}$ and $\mathrm{KCl}$ solutions suggests that $\mathrm{Mg}^{2+}$ (most likely $\mathrm{Mg}^{2+}$ hexahydrate) [51] interacts with DPPC in a manner similar to monovalent ions, i.e., with one cation binding per lipid headgroup (1:1 binding). This is likely due to the preference of $\mathrm{Mg}^{2+}$ to strongly retain its solvation 
shell [51]. Density functional theory calculations have determined that the net charge of a solvated $\mathrm{Mg}^{2+}$ ion is +1.29 , which could account for the similar behavior to monovalent ions [52].

$\mathrm{CaCl}_{2}$ solutions have the opposite effect on DPPC compared to $\mathrm{MgCl}_{2}$, resulting in a condensation of the monolayer (Fig. 1d). Isotherms at all concentrations occupy a smaller MMA relative to DPPC on water (Fig. 2a). The only exception is the LE phase, which is expanded relative to water (Fig. 2b). The condensation effect becomes more enhanced with increasing concentration, as observed by the decrease in the surface pressure of the LE-LC phase as the $\mathrm{Ca}^{2+}$ concentration increases. Results presented here contradict previously published studies including work from our group and others, in which an expansion of the PC monolayer occurred on $\mathrm{CaCl}_{2}$ solutions $[15,40,53-55]$. However, large discrepancies exist between reported results. For example Lee et al. reported a large expansion $\left(\sim 15 \AA^{2} /\right.$ molecule $)$ in the LE phase for a $0.2 \mathrm{mM} \mathrm{CaCl}$ solution [54], while other studies showed only small MMA increases $\left(\leq 1 \AA^{2} /\right.$ molecule) for $5 \mathrm{mM}$ and $0.1 \mathrm{M}$ solutions [53,56]. More recent studies done in our group have demonstrated the impact of salt purity and purification method on interfacial measurements [28], especially when investigating ion binding to lipids [57]. Furthermore, studies done by Kewalramani et al. on dimyristoylphosphatidylcholine (DMPC) monolayers found that aqueous solutions made from unbaked salts impacted the surface pressure at which the DMPC LE-LC coexistence phase occurred [58]. They further showed that $\mathrm{Ca}^{2+}$ lowered the LE-LC transition pressure relative to water by $4.3 \mathrm{mN} / \mathrm{m}$; $\mathrm{Mg}^{2+}$ also lowered the transition pressure, but to a much lesser extent $(0.7 \mathrm{mN} / \mathrm{m})$. Results presented here for the lowest concentration $(0.3 \mathrm{M})$ are consistent with that study 
as the LE-LC transition pressure was lowered by $0.8 \mathrm{mN} / \mathrm{m}$ for $\mathrm{Ca}^{2+}$, but was not significantly changed for $\mathrm{Mg}^{2+}$. While showing similar trends, direct comparisons to the study by Kewalramani et al. are difficult to make as the lipid of interest (DMPC), temperature $\left(15^{\circ} \mathrm{C}\right)$, and ion concentration $(150 \mathrm{mM})$ were significantly different than those used here. Yet, Kewalramani et al. noted that the purity of salts influenced the phase behavior of the phospholipid, which demonstrates the importance of removing organic contaminants when investigating lipid-ion systems. This factor could explain, at least in part, some of the differences observed between in isotherms presented here and those reported previously in the literature.

The opposing trends observed in DPPC isotherms on $\mathrm{MgCl}_{2}$ and $\mathrm{CaCl}_{2}$ solutions suggest that these divalent cations interact differently with the PC headgroup. In the presence of $\mathrm{Ca}^{2+}$, DPPC molecules are able to pack more tightly as evidenced by the 2 $\AA^{2} /$ molecule decrease in molecular area in the LC phase (Fig. 2a). In order for the molecular area to decrease, two possible scenarios can occur: (1) $\mathrm{Ca}^{2+}$ acts as a bridge between two neighboring lipids, forming a 2:1 DPPC: $\mathrm{Ca}^{2+}$ complex; (2) $\mathrm{Ca}^{2+}$ causes the reorientation of the $\mathrm{PC}$ headgroup. Binding constant calculations and $\mathrm{MD}$ simulations have both found that formation of $2: 1$ complexes are more probable than 1:1 complexes $[46,55]$. Yet, recent surface potential measurements suggest that reorientation of the PC headgroup occurs in highly concentrated $\mathrm{Ca}^{2+}$ solutions (2 M) [34]. Both scenarios likely occur to some degree, but more sensitive techniques such as nuclear magnetic resonance (NMR) or vibrational sum frequency generation (VSFG) spectroscopy are needed to clarify this. In the case of $\mathrm{Mg}^{2+}$, its behavior is similar to that of a monovalent ion. Free energies of hydration of the cation were also considered in evaluating the trend observed. 
However, expansion or condensation of the monolayer appears independent of this parameter. Note that the values for free energy of hydraton (energy required to remove one water molecule from cation's solvation shell) are as follows [59]: $\mathrm{K}^{+}\left(\mathrm{H}_{2} \mathrm{O}\right)_{2.6}: 295$ $\mathrm{kJ} / \mathrm{mol} ; \mathrm{Na}^{+}\left(\mathrm{H}_{2} \mathrm{O}\right)_{3.5}: 365 \mathrm{~kJ} / \mathrm{mol} ; \mathrm{Ca}^{2+}\left(\mathrm{H}_{2} \mathrm{O}\right)_{7.2}: 1505 \mathrm{~kJ} / \mathrm{mol} ; \mathrm{Mg}^{2+}\left(\mathrm{H}_{2} \mathrm{O}\right)_{10.0}: 1830$ $\mathrm{kJ} / \mathrm{mol}$.

To determine the influence of cation enrichment on the rigidity of the monolayer the isothermal compressibility modulus $\left(C_{s}^{-1}=-A_{\Pi}\left(\partial \Pi / \partial A_{\Pi}\right)_{T}\right.$, where $A_{\Pi}$ is the molecular area at the corresponding П) was obtained from the slope of each compression isotherm shown in Fig. 1. The compressibility modulus of the DPPC monolayer on water is shown in Fig. 3a. With increasing surface pressure the compressibility modulus first reaches a maximum value of $\sim 25 \mathrm{mN} / \mathrm{m}$ before decreasing back to $0 \mathrm{mN} / \mathrm{m}$ at a surface pressure of $8.4 \mathrm{mN} / \mathrm{m}$, which corresponds to the LE-LC coexistence phase. As surface pressure further increases past this point, the compressibility modulus reaches a maximum value of $200 \mathrm{mN} / \mathrm{m}$, indicative of a monolayer in the LC phase [60]. Finally, the compressibility modulus returns to $0 \mathrm{mN} / \mathrm{m}$ when the monolayer approaches its collapse pressure. Experimental values of compressibility modulus reported here for each phase of DPPC are in good agreement with those found in literature [61,62]. Surprisingly, no significant change in the compressibility modulus was observed in the LC phase for any cation investigated. This implies that the rigidity of the DPPC monolayers in the LC phase does not depend on the cation identity or concentration. The only salt-induced effect observed in the compressibility modulus is a small change in the surface pressure at which the LE-LC phase occurred (Figs. 3a,b). $\mathrm{Na}^{+}$and $\mathrm{K}^{+}$have similar surface pressure values, which are higher than water at all concentrations. An increase in the 
surface pressure of the LE-LC phase relative to water indicates a stabilization of the monolayer. In contrast, the monolayer becomes less stable with increasing $\mathrm{Ca}^{2+}$ concentration, as a decrease in the surface pressure occurs. For $\mathrm{Mg}^{2+}$ the surface pressure remains essentially unchanged from that on water for salt concentrations below $2.0 \mathrm{M}$. However, a significant increase in surface pressure occurs for $4.0 \mathrm{M} \mathrm{Cl}^{-}$, suggesting that stabilization of DPPC does not occur until there is a significant enrichment of $\mathrm{Mg}^{2+}$ ions at the interface.

3.2 Cation identity and salt concentration effects on the surface morphology of DPPC monolayers

The surface morphology of DPPC monolayers on water in all phases is consistent with literature [63], but results presented here focus on the LE-LC phase as the surface morphology in this region is most impacted by the presence of ions. BAM images presented in Fig. 4 show the surface morphology of DPPC in the LE-LC phase on water, $\mathrm{NaCl}$, and $\mathrm{KCl}$ solutions. Darker (or black) and brighter regions in the images represent, respectively, lipid-poor and lipid-rich areas. It can be seen that on water, small $(30 \mu \mathrm{m})$, multi-lobed lipid domains are present. At low concentrations $(0.6 \mathrm{M})$, both $\mathrm{Na}^{+}$and $\mathrm{K}^{+}$ appear to have little influence on the surface morphology compared to water, as similar small, multi-lobed domains are observed. Yet, the number density of DPPC LC domains has increased relative to water (Table 1 ), with $\mathrm{K}^{+}$having a larger number density than $\mathrm{Na}^{+}$. Concurrently, the average size of domains decreases as number density increases. Based on nucleation theory, the size and number of domains formed in the coexistence region depends on their free energy, which is related to the competing effects of line 
tension and electrostatic repulsion [64]. Line tension arises from van der Waal interactions of alkyl chains, and favors formation of circular domains. Electrostatic repulsions cause formation of elongated structures that are often branched or dendritic in shape. A lower line tension causes an increased number of domains of smaller size to form [65]. The higher number of smaller sized domains observed in the presence of monovalent cations stems from increased disorder in the monolayer (i.e. expansion) as ions compete with DPPC molecules to occupy surface sites, which leads to decreased line tension and increased electrostatic repulsions.

Alterations to the surface morphology do occur at high concentrations. In the case of 2.0 M NaCl, domains are much smaller (15-20 $\mu \mathrm{m})$, tightly packed, and darker (less contrast), suggesting that the refractive index or thickness of the monolayer has changed. Similarly, darkening of the image occurs for $2.0 \mathrm{M} \mathrm{KCl}$, but the monolayer forms an inhomogeneous film with no distinct domains apparent. In general, it seems that monovalent ions do not influence the surface morphology of the monolayer until they reach sufficient concentration in the interfacial region.

Divalent cations, however, have a distinct impact on the surface morphology even at low concentrations. BAM images in Fig. 5 show the surface morphology of the LE-LC phase of DPPC on $\mathrm{CaCl}_{2}$ and $\mathrm{MgCl}_{2}$ solutions at 0.3 , 1.0, and 2.0 M. On $0.3 \mathrm{M} \mathrm{CaCl}_{2}$ solutions DPPC forms domains that are on average less than half the size as those on water. The number density of LC domains increases by five-fold relative to water (Table 1), and domains are circular in shape instead of multilobed, indicating that an increase in line tension occurs in the presence of $\mathrm{Ca}^{2+}[66]$. The decrease in size and increase in number density is consistent with fluorescence microscopy studies of DPPC on $\mathrm{CaCl}_{2}$ 
solutions $(\leq 1.0 \mathrm{M})[40,53]$. As the concentration of $\mathrm{CaCl}_{2}$ increases to $1.0 \mathrm{M}$, an inhomogeneous monolayer develops in which individual domains can no longer be distinguished. At 2.0 M the monolayer inhomogeneity persists, but the image is darker relative to $1.0 \mathrm{M} \mathrm{CaCl}_{2}$. Compared to water, domains on $0.3 \mathrm{M} \mathrm{MgCl}_{2}$ are also smaller and more numerous. This is somewhat surprising considering that the isotherm showed little deviation from that of water Yet, BAM reveals that $\mathrm{Mg}^{2+}$ also causes an increased number of domains that are smaller in size. It can be seen that, unlike $\mathrm{Ca}^{2+}$, domains retain their multilobed shape in the presence of $\mathrm{Mg}^{2+}$, which indicates that electrostatic repulsions are the dominant interfacial force. The observed changes in the surface morphology arise from decreased line tension, similar to the monovalent ions. DPPC molecules form an inhomogeneous monolayer on $1.0 \mathrm{M} \mathrm{MgCl}_{2}$, which becomes darker on 2.0 $\mathrm{M} \mathrm{MgCl}_{2}$. Comparison of the 1.0 and $2.0 \mathrm{M}$ solutions shows that DPPC monolayers formed on $\mathrm{MgCl}_{2}$ appear to be more compact than on $\mathrm{CaCl}_{2}$. Although $\mathrm{Mg}^{2+}$ and $\mathrm{Ca}^{2+}$ have opposite effects on DPPC phase behavior (i.e., expansion vs. condensation), imaging of the surface morphology shows that both divalent cations cause a larger number of smaller domains to form, albeit by different mechanisms.

In general, BAM images obtained on highly concentrated solutions, with the exception of $\mathrm{K}^{+}$, show a significant decrease in the monolayer reflectivity. Darkening of the images cannot be attributed to changes in the Brewster angle, as the Brewster angle was set for each aqueous solution to have the same initial reflected gray level for the bare solution surface. Two scenarios could possibly explain this observation: (1) fluidization of the monolayer occurs, where overall ordering of the alkyl chains decreases due to an increase of gauche defects in the chain, thus resulting in changes to relative thickness or 
refractive index; (2) alterations in the alkyl chain orientation, in which highly ordered chains (trans conformation) become more parallel to the aqueous surface, which would also change the relative thickness or refractive index of the monolayer. As a decrease in reflectivity was observed for both LE-LC and LC phases (see Fig. S4, Supplementary Material), it is unlikely that fluidization of the monolayer occurs since DPPC molecules were able to reach surface pressures of $55 \mathrm{mN} / \mathrm{m}$ or greater on all solutions, indicating that highly ordered films with strong van der Waals interactions are formed. This is further supported by IRRAS measurements, which is discussed in more detail in the next section.

If it is assumed that the thickness of a homogeneous, highly ordered monolayer remains roughly constant, then calculations reveal that the monolayer refractive index in the LC phase $(\Pi=45 \mathrm{mN} / \mathrm{m})$ changes with salt concentration (Figure 6. See Table $\mathrm{S} 2$ for calculated $\mathrm{n}_{\mathrm{m}}$ values). Increasing salt concentration results in a decrease in refractive index, regardless of cation identity. While changes in the refractive index relative to water seem somewhat small $\left(\sim 10^{-2}\right)$, ellipsometry studies have determined that the refractive index of DPPC on water increases by 0.021 from the LE to LC phase [67], showing how the alkyl chain conformation dictates the monolayer refractive index. DPPC monolayers on divalent chloride solutions have a smaller refractive index compared to monovalent ones $\left(n_{m}=1.457\right.$ vs. 1.478$)$ at the highest concentration measured. This indicates that divalent cations have a greater influence on the alkyl chains conformation and is consistent with previous studies [68]. However, comparison of values at the same chloride concentration $\left(2 \mathrm{M} \mathrm{Cl}^{-}\right)$, shows that the refractive index is smaller for 
monovalent ions than $\mathrm{Mg}^{2+}$. This finding is in line with $\Pi-A$ isotherms that suggested $\mathrm{Mg}^{2+}$ interacts with DPPC in a manner similar to a monovalent ion (1:1 binding).

3.3 Cation identity and salt concentration effects on the intermolecular interactions of DPPC monolayers

\subsubsection{IRRAS: CH region}

IRRAS spectra were collected in the LE-LC phase $\left(70 \AA^{2} /\right.$ molecule with respective surface pressures shown in Fig. $3 b)$ and the $\mathrm{LC}$ phase $(40 \mathrm{mN} / \mathrm{m})$ to provide additional information on the effect of highly concentrated cations on a DPPC monolayer. Peak positions of the methylene $\left(\mathrm{CH}_{2}\right)$ vibrational modes are sensitive to the conformational order of the alkyl chains, and can provide insight into the relative number of trans and gauche conformations in the monolayer. A shift to lower wavenumbers indicates that the alkyl chains have more trans bonds [69]. Such a trend can be observed in Fig. 6, where the $\mathrm{CH}_{3}$ asymmetric $\left(\mathrm{CH}_{3}\right.$-as), $\mathrm{CH}_{2}$ asymmetric $\left(\mathrm{CH}_{2}\right.$-as), and $\mathrm{CH}_{2}$ symmetric $\left(\mathrm{CH}_{2}\right.$-ss $)$ modes at 2963, 2922 and $2853 \mathrm{~cm}^{-1}$, respectively, shift to lower wavenumbers when DPPC is compressed to a higher surface pressure [39]. Spectra of DPPC on $2.0 \mathrm{M} \mathrm{NaCl}$ and $2.0 \mathrm{M} \mathrm{CaCl}_{2}$ solutions (Fig. $7 \mathrm{~b}, \mathrm{c}$ ) show a shift to lower wavenumbers relative to water (Fig. 7a), even in the LE-LC phase. The shift induced by $\mathrm{Ca}^{2+}$ is larger than $\mathrm{Na}^{+}$in the LE-LC phase, indicating that alkyl chains are more ordered

in the presence of $\mathrm{Ca}^{2+}$, but no difference in peak position is observed for the two ions in the LC phase. It is especially interesting that $2.0 \mathrm{M} \mathrm{Na}^{+}$increases the order of the alkyl chains in the LE-LC phase as the П-A isotherms showed an expansion of the monolayer 
at this concentration. Previous experimental studies have found that concentrated $\mathrm{NaCl}$ and $\mathrm{NaI}$ solutions disrupt chain ordering at low surface pressures [39,40], but MD simulations report that $\mathrm{Na}^{+}$induces a higher ordering of the chains $[46,70]$.

Fig. 8 displays the peak position of the $\mathrm{CH}_{2}$-as mode as function of $\left[\mathrm{Cl}^{-}\right]$for all ions investigated. In the LE-LC phase (Fig. 8a), $\mathrm{K}^{+}, \mathrm{Na}^{+}$, and $\mathrm{Ca}^{2+}$ cause the peak position to shift to lower wavenumbers with increasing $\left[\mathrm{Cl}^{-}\right]$. This suggests that alkyl chain conformation is dependent upon the cation concentration. Comparison of the peak position for monovalent ions to $\mathrm{Ca}^{2+}$ reveals that monovalent ions induce a higher degree of ordering. Due to their smaller size, monovalent ions may interact with the carbonyl group of the lipid chains [46], which could cause higher ordering and explain the increased MMA in the $\Pi-A$ isotherms. The LC phase seems to be less impacted by the cations than the coexistence phase (Fig. 8b), as shifts in the peak position of the DPPC alkyl chain $\mathrm{CH}_{2}$-as mode are less than $1 \mathrm{~cm}^{-1}$ from the value measured on water. Generally, it can be seen that with the exception of $0.3 \mathrm{M} \mathrm{MgCl}_{2}$, the alkyl chains are slightly more ordered in the presence of cations. It is likely that at high surface pressures cations are squeezed out of the monolayer and primarily interact with the hydrophilic portion of the lipid.

Unlike the other cations, $\mathrm{Mg}^{2+}$ causes the $\mathrm{CH}_{2}$-as vibration to shift to higher wavenumbers in the LE-LC phase, independent of salt concentration, and indicates that gauche defects exist in the alkyl chain. Fig. 9 shows spectra of DPPC on $\mathrm{MgCl}_{2}$ solutions in the coexistence region. It can be seen that the intensity of the $\mathrm{CH}_{2}$-as and $\mathrm{CH}_{2}$-ss peaks decreases on $\mathrm{MgCl}_{2}$ solutions compared to water. For $0.3 \mathrm{M} \mathrm{Mg}^{2+}$ a feature appears in the spectrum at $2883 \mathrm{~cm}^{-1}$ that can be attributed to the $\mathrm{CH}_{3}$ symmetric stretch $\left(\mathrm{CH}_{3}-\mathrm{ss}\right)$. The 
appearance of this vibrational mode confirms that gauche defects exist within the alkyl chain, as the existing IRRAS polarization is sensitive to orientation of the terminal methyl, which indirectly reports on gauche vs. trans bonds in the alkyl chains. This feature disappears for higher concentrations of $\mathrm{Mg}^{2+}$, but the intensity of the methylene peaks do not change, indicating that the relative number density or orientation of DPPC molecules remains the same for the three different concentrations. Spectra collected here suggest that the interaction of $\mathrm{Mg}^{2+}$ with DPPC is unique, but П-Area isotherms indicated that $\mathrm{Mg}^{2+}$ behaves similarly to monovalent ions. From $\Delta \mathrm{A}$ plots (Figure $2 \mathrm{~b}$ ), it can be seen the expansion of DPPC is twice that of both $\mathrm{Na}^{+}$and $\mathrm{K}^{+}\left(18\right.$ vs. $9 \AA^{2} /$ molecule), which is likely due increased electrostatic repulsions from the +2 charge of magnesium. The increased space between molecules could allow for the formation of gauche defects to occur in the presence of $\mathrm{Mg}^{2+}$. A 1:1 binding is still likely for $\mathrm{Mg}^{2+}$ ions (which are hydrated, $\left.\mathrm{Mg}^{2+} \cdot 6 \mathrm{H}_{2} \mathrm{O}\right)$ as IRRAS spectra of the phosphate region, discussed in the next

section, show that $\mathrm{Mg}^{2+}$ has similar interactions with the phosphate moiety as monovalent ions.

\subsubsection{IRRAS: Phosphate region}

Vibrational modes of phospholipid headgroups have been well characterized and used to determine the degree of interaction that cations have with the negatively charged phosphate group [68,71,72]. Spectra of the phosphate vibrational modes of DPPC on 2.0 $\mathrm{M} \mathrm{KCl}$ in the LE-LC and LC phases are shown in Fig. 10. The asymmetric and symmetric $\mathrm{PO}_{2}^{-}$stretching $\left(\mathrm{PO}_{2}{ }^{-}\right.$-as and $\mathrm{PO}_{2}{ }^{-}$-ss $)$modes are observed at 1230 and 1087 $\mathrm{cm}^{-1}$, respectively. Peaks at 1170 and $1070 \mathrm{~cm}^{-1}$ can be attributed to the CO-O-C 
asymmetric and symmetric stretches (CO-O-C-as and CO-O-C-ss) of the carbonyl esters [71,72]. A C-O-P-O-C stretch is known to occur at $1060 \mathrm{~cm}^{-1}$, and is sometimes discernable from the CO-O-C-ss. The feature at $975 \mathrm{~cm}^{-1}$ is attributed to $\mathrm{N}-\left(\mathrm{CH}_{3}\right)_{3}$ asymmetric stretches of the choline group. The shoulder observed on the $975 \mathrm{~cm}^{-1}$ band, located at $950 \mathrm{~cm}^{-1}$, is generally thought to be due to C-N asymmetric stretching of the choline as well [71].

Compression of the DPPC monolayer to a higher surface pressure on $2.0 \mathrm{M} \mathrm{KCl}$ leads to an increase in the intensity of all peaks due to increased number density of DPPC molecules. Shifts in the $\mathrm{PO}_{2}{ }^{-}$-as and $\mathrm{PO}_{2}{ }^{-}$-ss to higher wavenumbers are likely caused by the ion-induced dehydration of the phosphate group. For all four cations studied here, phosphate group dehydration was observed in the LC phase, consistent with previously reported literature, where dehydration occurs upon monolayer compression regardless of whether ions are present in the solution $[15,23,39]$.

To reveal this ion-induced dehydration of the phosphate group, the peak position of the $\mathrm{PO}_{2}^{-}$-as mode in the presence of each cation is plotted as a function of $\left[\mathrm{Cl}^{-}\right]$for both the LE-LC and LC phases (Fig. 11). For the coexistence phase a shift to lower wavenumbers relative to water is observed for $\mathrm{Na}^{+}, \mathrm{K}^{+}$, and $\mathrm{Mg}^{2+}$, indicating that the phosphate headgroup is more hydrated in the presence of these particular cations. In the LC phase, however, neither $\mathrm{Na}^{+}$nor $\mathrm{K}^{+}$influence the peak position of this mode. This is also consistent with studies by Binder et al. and Maltseva et al. [68,72], which found that monovalent ions did not alter the peak position of this mode in the condensed phase. The difference in behavior between the LE-LC and LC phase observed here suggests that at low lipid coverage monovalent cations have little or no interaction with the phosphate 
moiety, instead likely interacting with the carbonyl group. As the monolayer is compressed ions are forced away from the carbonyls, where they weakly interact with the phosphate group.

It is apparent from Fig. 11 that the interaction of $\mathrm{Mg}^{2+}$ and $\mathrm{Ca}^{2+}$ ions with the phosphate moiety is very different. As previously noted, in the LE-LC phase $\mathrm{Mg}^{2+}$ increases hydration of the phosphate group relative to water. The largest decrease in peak frequency occurs for $0.6 \mathrm{M} \mathrm{Cl}^{-}$. After this point the peak frequency increases until it recovers at $4.0 \mathrm{M} \mathrm{Cl}^{-}$the same value as DPPC monolayers on water. $\mathrm{Mg}^{2+}$ ions are known to retain their first and second solvation shells at low concentrations, but as $\left[\mathrm{Mg}^{2+}\right]$ increases there are an insufficient number of water molecules to complete the second solvation shell [73]. This could account for the increased headgroup hydration at low concentrations followed by dehydration with increasing concentration. In the LC phase $\mathrm{Mg}^{2+}$ causes dehydration of the headgroup with increasing concentration, consistent with previous studies $[68,72]$.

$\mathrm{Ca}^{2+}$, unlike $\mathrm{Mg}^{2+}$, induces dehydration of the phosphate group in both the LE-LC and LC phases. Dehydration is much more apparent in the LC phase (Fig. 11), as the increase in peak position to higher wavenumbers is larger for 0.6 and $2.0 \mathrm{M} \mathrm{Cl}^{-}$in this phase compared to LE-LC phase. Interestingly, a large shift from 1232 to $1242 \mathrm{~cm}^{-1}$ is observed from 2.0 to $4.0 \mathrm{M} \mathrm{Cl}^{-}$in the LE-LC phase. Studies by Casillas-Ituarte et al. reported a $9 \mathrm{~cm}^{-1}$ shift of the $\mathrm{PO}_{2}^{-}$-ss mode in the presence of $\mathrm{Ca}^{2+}$ when comparing silica-supported (dehydrated) monolayers and monolayers on aqueous solutions [15]. A significant shift $\left(11 \mathrm{~cm}^{-1}\right)$ of the $\mathrm{PO}_{2}^{-}$-ss mode was also observed here, as can be seen in Fig. 12. These spectra show the phosphate region of DPPC in the LE-LC phase on $\mathrm{CaCl}_{2}$ 
solutions at various salt concentrations. It is notable for the $2.0 \mathrm{M}$ solution that, in addition to shifts in the $\mathrm{PO}_{2}{ }^{-}$modes, the asymmetric mode narrows significantly while the symmetric mode broadens. These features were similarly observed in the LC phase, indicating that dehydration is independent of lipid packing density. This finding suggests that the phosphate moiety is substantially dehydrated in the presence of $2.0 \mathrm{M} \mathrm{CaCl}_{2}$, and that there may be a change in the orientation of the PC headgroup as the transition moment strength of the phosphate modes has changed. Femtosecond IR pump-probe

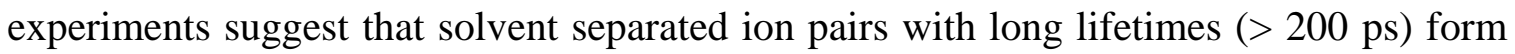

between $\mathrm{Ca}^{2+}$ ions and phospholipid headgroups [74]. The formation of strong ion pairs at high concentrations could contribute to the changes observed for the $\mathrm{PO}_{2}^{-}$-ss mode. Recent surface potential measurements of DPPC monolayers on $\mathrm{CaCl}_{2}$ solutions have indicated that there is a reorientation of the headgroup in the high concentration regime [34], but more sensitive measurements are needed to accurately determine if this is the case.

\section{Conclusions}

The goal of this study was to determine how the concentration of monovalent and divalent cations, especially in a highly concentrated regime, impacts the interfacial organization and structure of a DPPC monolayer, and to understand the mechanism of such. To the best of the authors' knowledge, this is the first time that lipid monolayers on such highly concentrated solutions have been studied. Surface pressure-area isotherms show that $\mathrm{Na}^{+}, \mathrm{K}^{+}$, and $\mathrm{Mg}^{2+}$ cause a monolayer expansion that increases with salt concentration, consistent with previous literature [40,49]. The phase behavior of $\mathrm{Ca}^{2+}$ 
contradicts previous reports $[15,40,55]$, demonstrating that purification of salt solutions is necessary as impurities cause contradictory results even for stated salt purities greater than $99 \%$. Imaging of the surface morphology reveals that increasing salt concentration leads to disruption of lipid packing, resulting in a monolayer that resembles an expanded state. IRRAS measurements, however, find that cations, with the exception of $\mathrm{Mg}^{2+}$, cause the alkyl chains to be more ordered on highly concentrated salts. Further analysis of BAM images indicates that the monolayer refractive index decreases with increasing salt concentration, suggesting that orientation of the alkyl chains changes as cations become enriched in the interfacial region. Probing of the headgroup-cation interactions with IRRAS revealed that monovalent cations had weak interactions with the phosphate group, consistent with literature $[68,72]$. The interaction of $\mathrm{Mg}^{2+}$ with the headgroup depended upon cation concentration and lipid packing density. Dehydration of the phosphate group occurred in the presence of $\mathrm{Ca}^{2+}$, in agreement with previous studies $[15,68,72]$, but substantial dehydration of the headgroup was observed for the first time in an aqueous environment when the lipid/aqueous interface was saturated with $\mathrm{Ca}^{2+}$ ions.

These results have implications for organic-coated aerosols, as several of the ions studied here have been found to be enriched in these aerosols $[11,13,14]$, especially $\mathrm{Mg}^{2+}$ [12]., Since the refractive index of a lipid monolayer is dependent on the concentration of ions in solution, results found here have the potential to aid climate modelers [75], as it is likely that the refractive index of organic-coated aerosols will change as the particle experiences loss or uptake of water from the environment. Furthermore, the ion concentration impacts the surface morphology (i.e., packing density) of lipid films, which will influence the rate of water exchange with the atmosphere, resulting in alterations to 
the size, reactivity, and ability of aerosol particles to scatter light and act as a cloud condensation nuclei [3]. In general, results found here indicate that properties of organiccoated aerosols will depend on the concentration of ions present.

\section{Author Information}

Corresponding Author

*Email address: allen@chemistry.ohio-state.edu. Tel: +1-614-292-4772; Fax: +1-614$292-1685$

\section{$\underline{\text { Present Address }}$}

${ }^{\dagger}$ C.B.C.: Department of Chemistry, The University of North Carolina at Chapel Hill, Campus Box 3290, Chapel Hill, North Carolina 27599, United States. 


\begin{abstract}
Abbreviations
DPPC: Dipalmitoylphosphatidylcholine; BAM: Brewster angle microscopy; IRRAS: Infrared Reflection-Absorption Spectroscopy; SSA: sea spray aerosols; OC: organic carbon; SSOC: sea-salt organic carbon; ATOFMS: aerosol time-of-flight mass spectrometry; STXM-NEXAFS: scanning transmission X-ray microscopy with near edge X-ray absorption fine structure; SSML: sea surface microlayer; П-A: surface pressuremolecular area; $\theta_{B}$ : Brewster angle; $n_{a}$ : refractive index of air; $n_{s}$ : refractive index of solution; $n_{m}$ : refractive index of monolayer; $R_{p}$ : reflectivity of p-polarized light; $d$ : monolayer thickness; $\lambda$ : wavelength; MMA: mean molecular area; MCT: HgCdTe; G: gas; LE: liquid-expanded; LC: liquid-condensed; DMPC: dimyristoylphosphatidylcholine; $\mathrm{CH}_{\mathrm{x}}-\mathrm{ss}: \mathrm{CH}_{\mathrm{x}}$ symmetric stretch; $\mathrm{CH}_{\mathrm{x}}$-as: $\mathrm{CH}_{\mathrm{x}}$ asymmetric stretch; $\mathrm{PO}_{2}^{-}-\mathrm{ss} ; \mathrm{PO}_{2}^{-}$symmetric stretch; $\mathrm{PO}_{2}{ }^{-}$-as: $\mathrm{PO}_{2}{ }^{-}$asymmetric stretch
\end{abstract}

\title{
Conflict of Interest
}

The authors declare no conflict of interest for this manuscript.

\section{Acknowledgements}

The authors would like to thank the National Science Foundation and the Center for Aerosol Impacts on Climate and Environment for funding this work with Grant CHE1305427. The authors would also like to thank Dr. Wei Hua, Bethany Wellen, and John Galden for their help in preparing solutions used in this study, and Dr. Dominique Verreault for countless discussions. 


\section{Supplementary Material}

Supplementary data associated with this manuscript can be found in the online version at http://dx.doi.org/10.0000/j.jcis.2016.00.000. This material includes (1) additional surface pressure-area isotherms and BAM images of DPPC monolayers on $0.3 \mathrm{M} \mathrm{MgCl}_{2}$ demonstrating reproducibility of measurements, (2) compressibility modulus curves of DPPC monolayers on aqueous salt solutions at different concentrations, (3) BAM images of DPPC monolayers in the LC phase on $\mathrm{MgCl}_{2}$ solutions of various concentrations, and (4) measured Brewster angles and calculated refractive indices of aqueous salt solutions. 


\section{References}

[1] M.Z. Jacobson, Global direct radiative forcing due to multicomponent anthropogenic and natural aerosols, J. Geophys. Res. 106 (2001) 1551-1568.

[2] B.J. Finlayson-Pitts, J.N. Pitts, Jr., Chemistry of the Upper and Lower Atmosphere, Academic Press, San Diego, 2000.

[3] D.K. Farmer, C.D. Cappa, S.M. Kreidenweis. Atmospheric processes and their controlling influence on cloud condensation nuclei activity, Chem. Rev. 115 (2015) 4199-4217.

[4] P.J. Demott, A.J. Prenni, X. Liu, S.M. Kreidenwies, M.D. Petters, C.H. Twohy, et al., Predicting global atmospheric ice nuclei distributions and their impacts on climate, Proc. Natl. Acad. Sci. U.S.A. 107 (2010) 11217-11222.

[5] D.J. Donaldson, V. Vaida, The influence of organic films at the air-aqueous boundary on atmospheric processes, Chem. Rev. 106 (2006) 1445-1461.

[6] K.A. Prather, T.H. Bertram, V.H. Grassian, G.B. Deane, M.D. Stokes, P.J. Demott, et al., Bringing the ocean into the laboratory to probe the chemical complexity of sea spray aerosol, Proc. Natl. Acad. Sci. U.S.A. 110 (2013) 7550-7555.

[7] C.D. O’Dowd, M.C. Facchini, F. Cavalli, D. Ceburnis, M. Mircea, S. Decesari, S. Fuzzi, Y.J. Yoon, J.P. Putaud, Biogenically driven organic contribution to marine aerosol, Nature. 431 (2004) 676-670.

[8] Y.J. Yoon, D. Ceburnis, F. Cavalli, O. Jourdan, J.-P. Putaud, M.C. Facchini, et al., Seasonal characteristics of the physiochemical properties of North Atlantic marine atmospheric aerosols, J. Geophys. Res. 112 (2007) D04206.

[9] M.C. Facchini, M. Rinaldi, S. Decesari, C. Carbone, E. Finessi, M. Mircea, et al., Primary submicron marine aerosol dominated by insoluble organic colloids and aggregates, Geophys. Res. Lett. 35 (2008) L17814.

[10] H. Fu, R. Ciuraru, Y. Dupart, M. Passananti, L. Tinel, S. Rossignol, et al., Photosensitized production of atmospherically reactive organic compounds at the air/aqueous interface, J. Am. Chem. Soc. 137 (2015) 8348-8351.

[11] D.B. Collins, D.F. Zhao, M.J. Ruppel, O. Laskina, J.R. Grandquist, R.L. Modini, et al., Direct aerosol chemical composition measurements to evaluate the physicochemical differences between controlled sea spray aerosol generation schemes, Atmos. Meas. Tech. 7 (2014) 3667-3683.

[12] A.P. Ault, R.C. Moffet, J. Baltrusaitis, D.B. Collins, M.J. Ruppel, L.A. CuadraRodriguez, et al., Size-dependent changes in sea spray aerosol composition and properties with different seawater conditions, Env. Sci Technol. 47 (2013) 56035612.

[13] X. Wang, C.M. Sultana, J. Trueblood, T.C.J. Hill, F. Malfatti, C. Lee, et al., Microbial control of sea spray aerosol composition: A tale of two blooms, ACS Central Sci. 1 (2015) 124-131.

[14] A.P. Ault, T.L. Guasco, O.S. Ryder, J. Baltrusaitis, L.A. Cuadra-Rodriguez, D.B. Collins, et al., Inside versus outside: Ion redistribution in nitric acid reacted sea spray aerosol particles as determined by single particle analysis, J. Am. Chem. Soc. 135 (2013). 14528-14531 
[15] N.N. Casillas-Ituarte, X. Chen, H. Castada, H.C. Allen, $\mathrm{Na}^{+}$and $\mathrm{Ca}^{2+}$ effect on the hydration and orientation of the phosphate group of DPPC at air-water and airhydrated silica surface, J. Phys. Chem. B. 114 (2010) 9485-9495.

[16] C.Y. Tang, H.C. Allen, Ionic Binding of $\mathrm{Na}^{+}$versus $\mathrm{K}^{+}$to the carboxylic acid headgroup of palmitic acid monolayers studied by vibrational sum frequency generation spectroscopy, J. Phys. Chem. A. 113 (2009) 7383-7393.

[17] C.Y. Tang, Z. Huang, H.C. Allen, Binding of $\mathrm{Mg}^{2+}$ and $\mathrm{Ca}^{2+}$ to palmitic acid and deprotonation of the $\mathrm{COOH}$ headgroup studied by vibrational sum frequency generation spectroscopy, J. Phys. Chem. B. 114 (2010) 17068-17076.

[18] E.M. Adams, H.C. Allen, Palmitic acid on salt subphases and in mixed monolayers of cerebrosides: Application to atmospheric aerosol chemistry, Atmosphere. 4 (2013) 315-336.

[19] Y. Li, M.J. Ezell, B.J. Finlayson-Pitts, The impact of organic coatings on light scattering by sodium chloride particles, Atmos. Envrion. 45 (2011) 4123-4132.

[20] R.M. Garland, M.E. Wise, M.R. Beaver, H.L. Dewitt, A.C. Aiken, J.L. Jimenez, et al., Impact of palmitic acid coating on the water uptake and loss of ammonium sulfate particles, Atmos. Chem. Phys. 5 (2005) 1951-1961.

[21] C.W. Dilbeck, B.J. Finlayson-Pitts, Hydroxyl radical oxidation of phospholipidcoated NaCl particles, Phys. Chem. Chem. Phys. 15 (2013) 9833.

[22] H. Nakahara, S. Nakamura, K. Nakamura, M. Inagaki, M. Aso, R. Higuchi, O. Shibata, Cerebroside Langmuir monolayers originated fromt echinoderms I. Binary systems of cerebrosides and phospholipids, Colloid Surf. B. 42 (2005) 157-174.

[23] G. Ma, H.C. Allen, DPPC langmuir monolayer at the air-water interface: Probing the tail and head groups by vibrational sum frequency generation spectroscopy, Langmuir. 22 (2006) 5341-5349.

[24] K.Y.C. Lee, Collapse mechanisms of Langmuir monolayers, Annu. Rev. Phys. Chem. 59 (2008) 771-791.

[25] L.F. Espinosa, S. Pantoja, L.A. Pinto, J. Rullkötter, Water column distribution of phospholipid-derived fatty acids of marine microorganisms in the Humboldt Current system off northern Chile, Deep-Sea Res. Part II. 56 (2009) 1063-1072.

[26] J. Brandsma, E.C. Hopmans, C.P.D. Brussaard, H.J. Witte, S. Schouten, J.S. Sinninghe Damste, Spatial distribution of intact polar lipids in North Sea surface waters: Relationship with environmental conditions and microbial community composition, Limnol. Ocean. 57 (2012) 959-973.

[27] F.J. Millero, Chemical Oceanography, 4th ed., CRC Press, Boca Raton, FL, 2015.

[28] W. Hua, D. Verreault, E.M. Adams, Z Huang. Impact of salt purity on interfacial water organization revealed by conventional and heterodyne-detected vibrational sum frequency generation spectroscopy, J. Phys. Chem. C. 117 (2013) 1957719585.

[29] A.C. Finlayson, The pH range of the Mohr titration for chloride ion can be usefully extended to 4-10.5, J. Chem. Educ. 69 (1992) 559.

[30] R.M. Prokop, A.W. Neumann, Measurments of the interfacial properties of lung surfactant, Curr. Opin. Colloid Interface Sci. 1 (1996) 677-681.

[31] E.C. Griffith, E.M. Adams, H.C. Allen, V. Vaida, Hydrophobic collapse of a stearic acid film by adsorbed L-phenylalanine at the air-water interface, J. Phys. Chem. B. 116 (2012) 7849-7857. 
[32] W.M. Haynes, CRC Handbook of Chemistry and Physics, 96th ed., CRC Press, Boca Raton, FL, 2015.

[33] C. Lheveder, S. Hénon, J. Meunier. Brewster angle microscopy. In: Physical Chemistry of Biological Interfaces (A. Baszkin, W. Norde, eds), Marcel Dekker, New York, NY, 2000.

[34] C.B. Casper, D. Verreault, E.M. Adams, W. Hua, H.C. Allen, Surface potential of DPPC monolayers on concentrated aqueous salt solutions, J. Phys. Chem. B. 10.1021/acs.jpcb.5b10483 (2016).

[35] J.M. Rodriguez Patino, C. Carrara Sánchez, M.R. Rodriguez Niño, Morphological and structural characteristics of monoglyceride monolayers at the air-water interface observed by Brewster angle microscopy, Langmuir. 15 (1999) 2484-2492.

[36] J. Miñones, Jr., S. Pais, J. Miñones, O. Conde, P. Dynarowics-Latka, Interactions between membrane sterols and phospholipids in model mammalian and fungi cellular membranes - A Langmuir monolyaer study, Biophys. Chem. 140 (2009) 69-77.

[37] M.C. Phillips, D. Chapman, Monolayer characteristics of saturated 1,2-Diacyl phosphatidylcholines (lecithins) and phosphatidylethanolamines at the air-water interface, Biochim. Biophys. Acta. 163 (1968) 301-313.

[38] V.L. Shapovalov, Interaction of DPPC monolayer at air-water interface with hydrophobic ions, Thin Solid Films. 327-329 (1998) 599-602.

[39] A. Aroti, E. Leontidis, E. Maltseva, G. Brezesinski, Effects of Hofmeister anions on DPPC Langmuir monolayers at air-water interface, J. Phys. Chem. B. 108 (2004) $15238-15245$.

[40] M. Sovago, G.W.H. Wurpel, M. Smits, M. Müller, M. Bonn, Calcium-induced phospholipid ordering depends on surface pressure, J. Amer. Chem. Soc. 129 (2007) 11079-11084.

[41] E. Leontidis, A. Aroti, L. Belloni, Liquid-expanded monolayers of lipids as model systems to understand the anionic Hofmeister series: 1. A tale of models, J. Phys. Chem. B. 113 (2009) 1447-1459.

[42] A.F. Eftaiha, M.F. Paige, The influence of salinity on surfactant miscibility in mixed dipalmitoylphosphatidylcholine - perfluorooctadecanoic acid monolayer films, J. Colloid. Interf. Sci. 353 (2011) 210-219.

[43] M. Christoforou, E. Leontidis, G. Brezesinski, Effects of sodium salts of lyotropic anions on low-temperature, ordered lipid monolayers, J. Phys. Chem. B. 116 (2012) $14602-14612$.

[44] A.D. Petelska, Z.A. Figazewski, The equilibria of lipid-K ${ }^{+}$ions in monolayer at the air/water interface, J. Membr. Biol. 244 (2011) 61-66.

[45] M. Arczewska, M. Gagos, Molecular organization of antibiotic amphotericin B in dipalmitoylphosphatidylcholine monolayers induced by $\mathrm{K}^{+}$and $\mathrm{Na}^{+}$ions: The Langmuir technique study, Biochim. Biophys. Acta. 1808 (2011) 2706-2713.

[46] A. Cordomi, O. Edholm, J.J. Perez, Effects of ions on a dipalmitoyl phosphatidylcholine bilayer: A molecular dynamics simulation study, J. Phys. Chem. B. 112 (2008) 1397-1408.

[47] A.A. Gurtovenko, I. Vattulainen, Effect of $\mathrm{NaCl}$ and $\mathrm{KCl}$ on phosphatidylcholine and phosphatidylehanolamine lipid membranes: Insight from atomic-simulations for 
understanding salt-induced effects in the plasma membrane, J. Phys. Chem. B. 112 (2008) 1953-1962.

[48] A.D. Petelska, Z.A. Figazewski, The equilibria between monovalent ions and phosphatidylcholine monolayers at the air/water interface, J. Membr. Biol. 246 (2013) 467-471.

[49] W. Ou-Yang, T. Yamamoto, T. Manaka, M. Iwamoto, Effect of external electrostatic charge on condensed phase domains at the air-water interface: Experiment and shape equation analysis, J. Chem. Phys. 130 (2009) 104706.

[50] A.D. Petelska, Z.A. Figazewski, Phosphatidylcholine - $\mathrm{Mg}^{2+}$ equilibria in a monolayer at the air/water interface, Dent. Eur. J. Chem. 11 (2013) 424-429.

[51] N.N. Casillas-Ituarte, K.M. Callahan, C.Y. Tang, X. Chen, M. Roeselova, D.J. Tobias, et al., Surface organization of aqueous $\mathrm{MgCl}_{2}$ and application to atmospheric marine aerosol chemistry, Proc. Natl. Acad. Sci. U.S.A. 107 (2010) 6616-6621.

[52] M. Pavlov, P.E.M. Siegbahn, M. Sandstrom, Hydration of Beryllium, Magnesium, Calcium, and Zinc Ions Using Density Functional Theory, J Phys Chem A. 102 (1998) 219-228.

[53] M. Ross, C. Steinem, H.-J. Galla, A. Janshoff, Visualization of chemical and physical properties of calcium-induced domains in DPPC/DPPS Langmuir-Blodgett layers, Langmuir. 17 (2001) 2437-2445.

[54] Y.-L. Lee, J.-L. Lin, C.-H. Chang, Thermodynamic characteristics and LangmuirBlodgett deposition behavior of mixed DPPA/DPPC monolayers at air/liquid interfaces, J. Colloid Interf. Sci. 296 (2006) 647-654.

[55] A.D. Petelska, A. Niemcunowicz-Janica, M. Szeremeta, Z.A. Figazewski, Equilibria of phosphatidylcholine - $\mathrm{Ca}^{2+}$ ions in monolayer at the air/water interface, Langmuir. 26 (2010) 13359-13363.

[56] S. Kundu, H. Matsuoka, H. Seto, Zwitterionic lipid (DPPC)-protein (BSA) complexes at the air-water interface, Colloid Surf. B. 93 (2012) 215-2218.

[57] Z. Huang, W. Hua, D. Verreault, H.C. Allen, Impact of salt purity on $\mathrm{Na}^{+}$and palmitic acid interactions, J. Phys. Chem. A. 117 (2013) 13412-13418.

[58] S. Kewalramani, H. Hlaing, B.M. Ocko, I. Kuzmenko, M. Fukuto, Effects of divalent cations on phase behavior and structure of a zwitterionic phospholipid (DMPC) monolayer at the air-water inteface, J. Phys Chem. Lett. 1 (2010) 489-495.

[59] Y. Marcus, A simple empirical model describing the thermodynamics of hydration of ions of widely varying charges, sizes, and shapes, Biophys. Chem. 51 (1994) 111-127.

[60] J.T. Davies, E.K. Rideal, Interfacial Phenomena, 2nd ed., New York, NY, 1963.

[61] S.L. Duncan, R.G. Larson, Comparing experimental and simulated pressure-area isotherms for DPPC, Biophys J. 94 (2008) 2965-2986.

[62] D.-M. Telesford, D. Verreault, V. Reick-Metrisin, H.C. Allen, Reduced condensing and ordering effects by 7-Ketocholesterol and 5 $\beta, 6 \beta$-epoxycholesterol on DPPC monolayers, Langmuir. 31 (2015) 9859-9869.

[63] X. Chen, Z. Huang, W. Hua, H. Castada, H.C. Allen, Reorganization and caging of DPPC, DPPE, DPPG, and DPPS monolayers caused by dimethylsulfoxide observed using Brewster angle microscopy, Langmuir. 26 (2010) 18902-18908. 
[64] A.W. Adamson, A.P. Gast, Physical Chemistry of Surfaces, 6th ed., Wiley, New York, NY, 1997.

[65] A. Arnold, I. Cloutier, A.M. Ritcey, M. Auger, Temperature and pressure dependent growth and morphology of DMPC/DSPC domains studies by Brewster angle microscopy, Chem. Phys. Lipids. 133 (2005) 165-179.

[66] P. Dhar, E. Eck, J.N. Israelachvili, D.W. Lee, Y. Min, A. Ramachandran, A.J. Waring, J.A. Zasadzinski, Lipid-protein interactions alter line tensions and domain size distributions in lung surfactant monolayers, Biophys J. 102 (2012) 56-65.

[67] D. Ducharme, J.-J. Max, C. Salesse, R.M. Leblanc, Ellipsometric study of the physical states of phosphatidylcholines at the air-water interface, J. Phys. Chem. 94 (1990) 1925-1932.

[68] H. Binder, O. Zschörnig, The effect of metal cations on the phase behavior and hydration characteristics of phospholipid membranes, Chem. Phys. Lipids. 115 (2002) 39-61.

[69] R. Mendelsohn, J.W. Brauner, A. Gericke, External infrared reflection absorption spectrometry of monolayer films at the air-water interface, Annu. Rev. Phys. Chem. 46 (1995) 305-334.

[70] S.A. Pandit, D. Bostick, M.L. Berkowitz, Molecular dynamic simulation of a dipalmitoylphosphatidylcholine bilayer with NaCl, Biophys J. 84 (2003) 37433750 .

[71] H.L. Casal, H.H. Mantsch, Polymorphic phase behavior of phospholipid membranes studied by infrared spectroscopy, Biochim. Biophys. Acta. 779 (1984) 381-401.

[72] E. Maltseva, V.L. Shapovalov, H. Möhwald, G. Brezesinski, Ionization state and structure of L-1,2-Ddipalmitoylphosphatidylglycerol monolayers at the liquid/air interface, J. Phys. Chem. B. 110 (2006) 919-926.

[73] K.M. Callahan, N.N. Casillas-Ituarte, M. Roeselova, H.C. Allen, D.J. Tobias, Solvation of magnesium dication: Molecular dynamics simulation and vibrational spectroscopic study of magnesium chloride in aqueous solutions, J Phys Chem A. 114 (2010) 5141-5148.

[74] S.T. van der Post, J. Hunger, M. Bonn, Bakker, H.J., Observation of water separated ion-pairs between cations and phospholipid headgroups, J. Phys. Chem. B. 118 (2014) 4397-4403.

[75] S.M. Burrows, O. Ogunro, A.A. Frossard, L.M. Russell, P.J. Rasch, S.M. Elliott, A physically based framework for modeling the organic fractionation of sea spray aerosol from bubble film Langmuir equilibira, Atmos. Chem. Phys. 14 (2014) 13601-13629. 


\section{FIGURES}

All figures are intended for color reproduction for both Web and print.
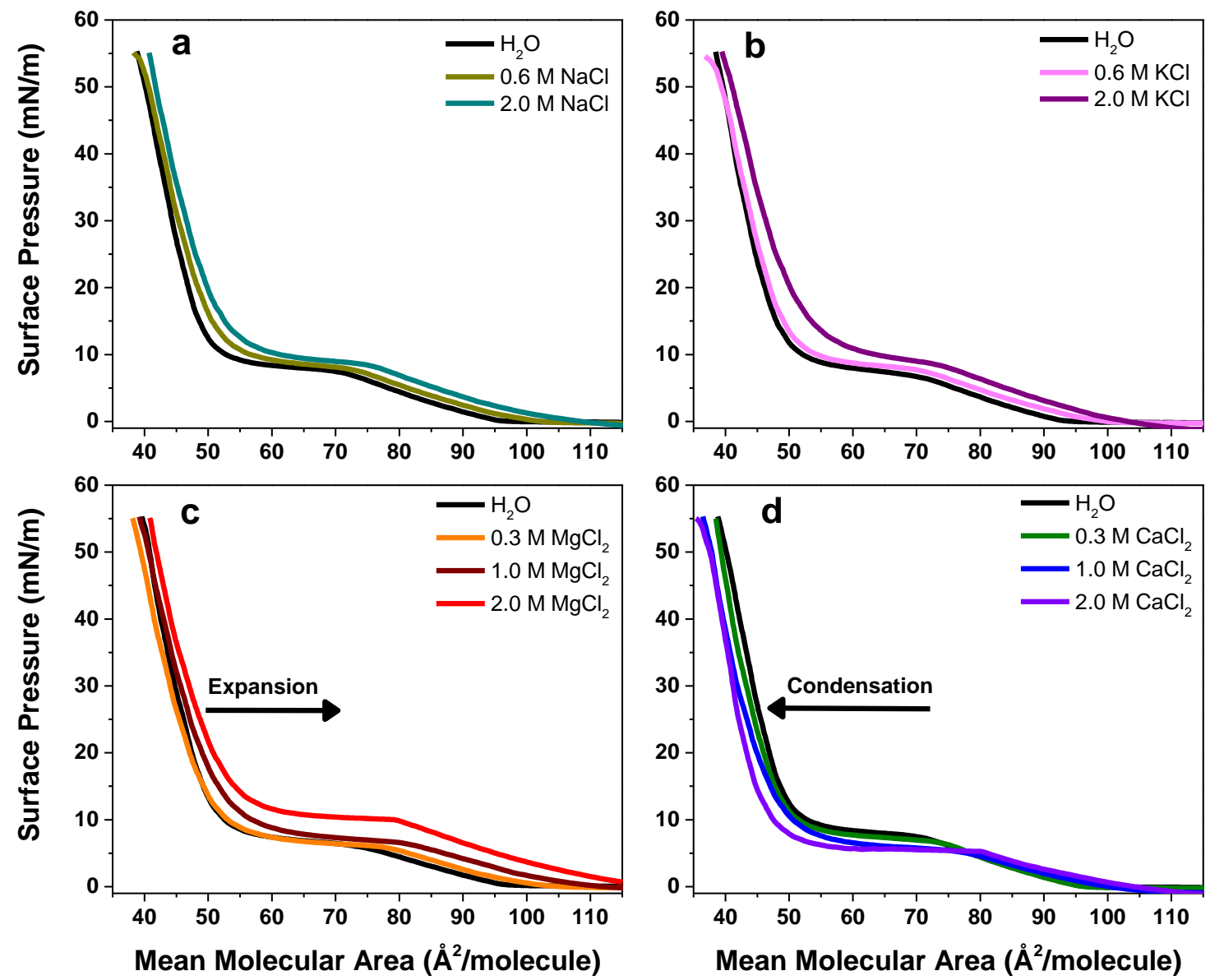

Fig. 1. Surface pressure-area isotherms of DPPC monolayers on (a) $\mathrm{NaCl}$, (b) $\mathrm{KCl}$, (c) $\mathrm{MgCl}_{2}$, and (d) $\mathrm{CaCl}_{2}$ solutions with varying salt concentrations. The collapse phase is not shown. $\mathrm{NaCl}$ and $\mathrm{KCl}$ salts expand the DPPC monolayers, while $\mathrm{MgCl}_{2}$ condenses or expands DPPC depending upon the phase and concentration. $\mathrm{CaCl}_{2}$ condenses the monolayer. 


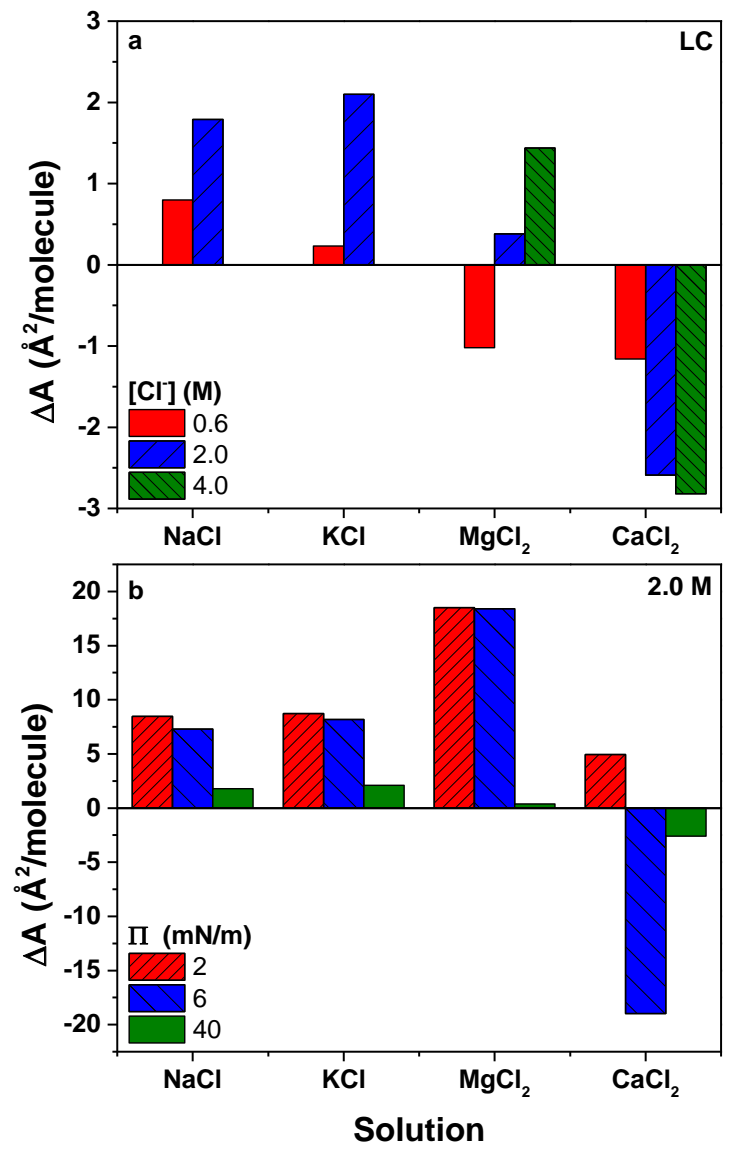

Fig. 2. Change in area for salt solutions relative to water for a.) $\mathrm{LC}$ phase $(40 \mathrm{mN} / \mathrm{m})$ for several salt concentrations b.) $2.0 \mathrm{M}$ salt solutions at different surface pressures. 

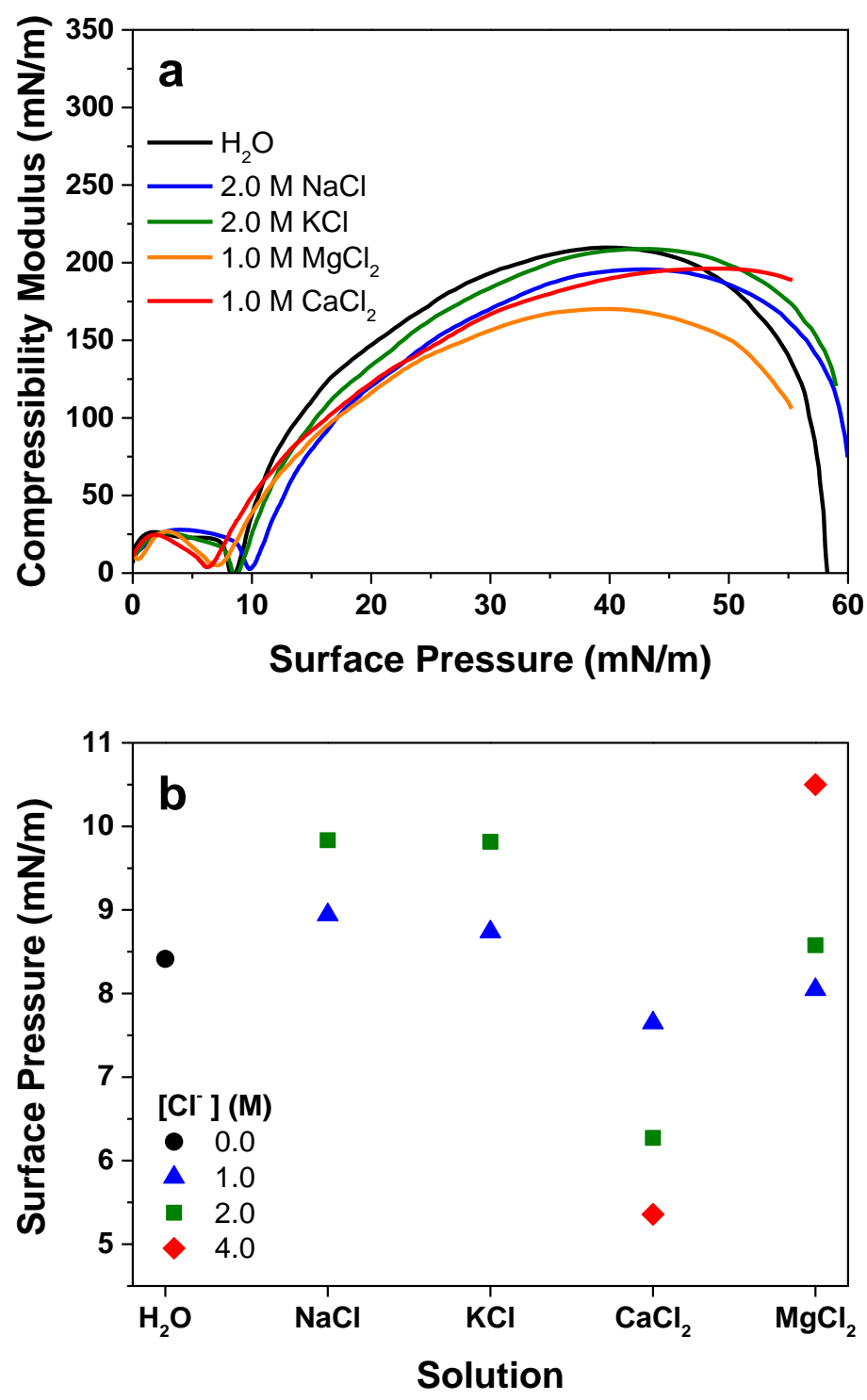

Fig. 3. (a) Compressibility modulus of DPPC monolayer on a water and $2.0 \mathrm{M} \mathrm{Cl}^{-}$salt solutions as a function of surface pressure. (b) Salt-induced effect on the surface pressure at which the LE-LC phase occurs. Stabilization of the monolayer occurs in the presence of $\mathrm{Na}^{+}, \mathrm{K}^{+}$, and $\mathrm{Mg}^{2+}$, but not $\mathrm{Ca}^{2+}$. 


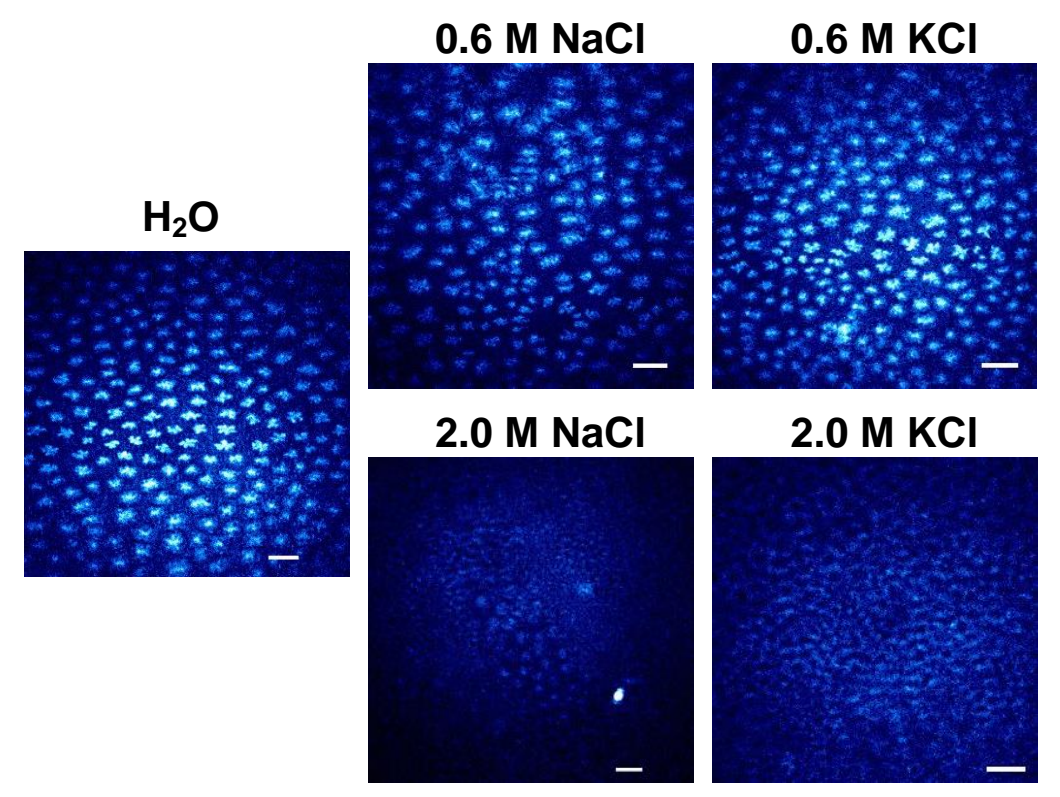

Fig. 4. BAM images of DPPC monolayers in the LE-LC phase on water, $\mathrm{NaCl}$, and $\mathrm{KCl}$ solutions. All images were taken at $70 \AA^{2} /$ molecule. Note the increased number density of DPPC LC domains and the presence of a population of smaller LC domains with the 2 M solutions. The scale bar is $50 \mu \mathrm{m}$. 


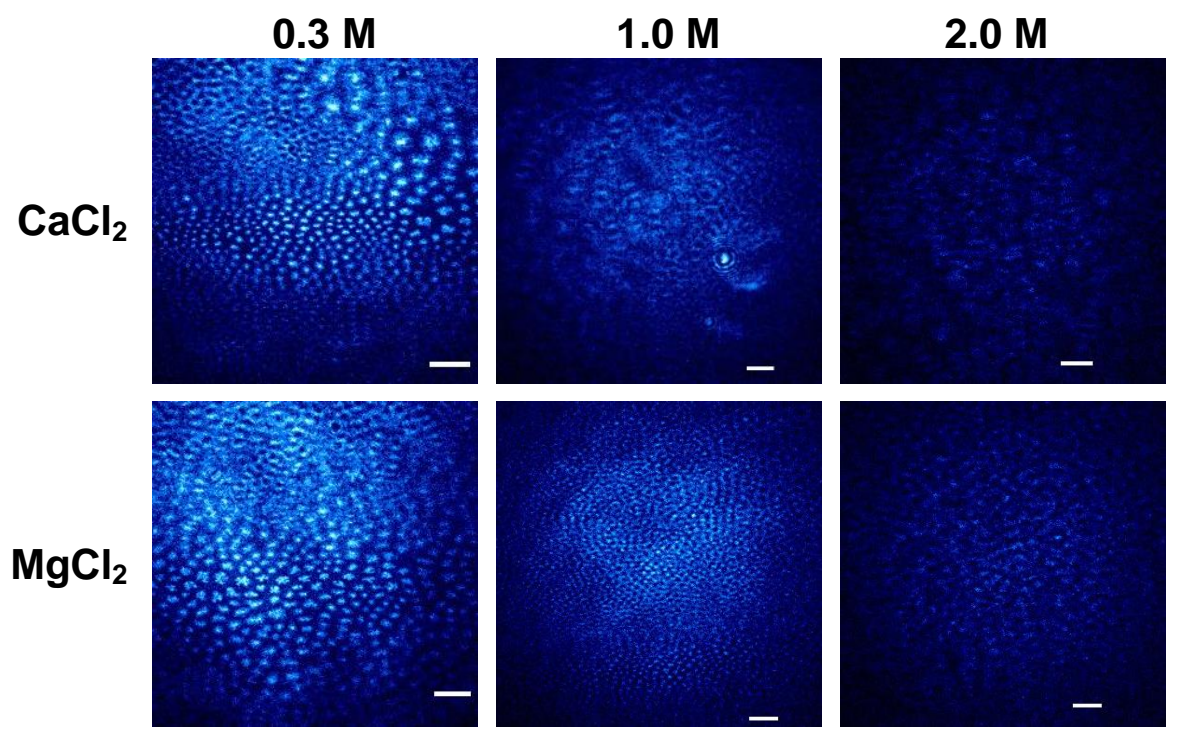

Fig.5. BAM images of DPPC monolayers in the LE-LC phase on $\mathrm{CaCl}_{2}$ and $\mathrm{MgCl}_{2}$ solutions with increasing concentration. All images were taken at $70 \AA^{2} /$ molecule. Note the increasing diffuseness of the domain structure as divalent salt concentrations are increased, and the variation of DPPC domain morphology, e.g., for $1 \mathrm{M} \mathrm{CaCl}_{2}$ vs. $\mathrm{MgCl}_{2}$ solutions. The scale bar is $50 \mu \mathrm{m}$. 


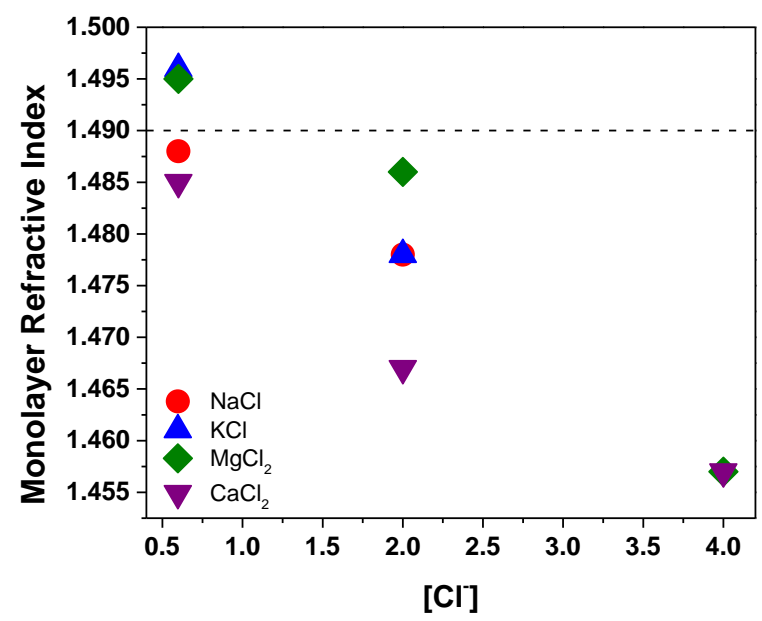

Fig. 6. Monolayer refractive index ( $\mathrm{n}_{\mathrm{m})}$ of $\mathrm{DPPC}$ on solutions of $\mathrm{NaCl}, \mathrm{KCl}, \mathrm{MgCl}_{2}$, and $\mathrm{CaCl}_{2}$ as a function of $\left[\mathrm{Cl}^{-}\right]$. The horizontal dashed line indicates the monolayer refractive index of DPPC on water. Refractive index decreases with increasing salt concentration. 


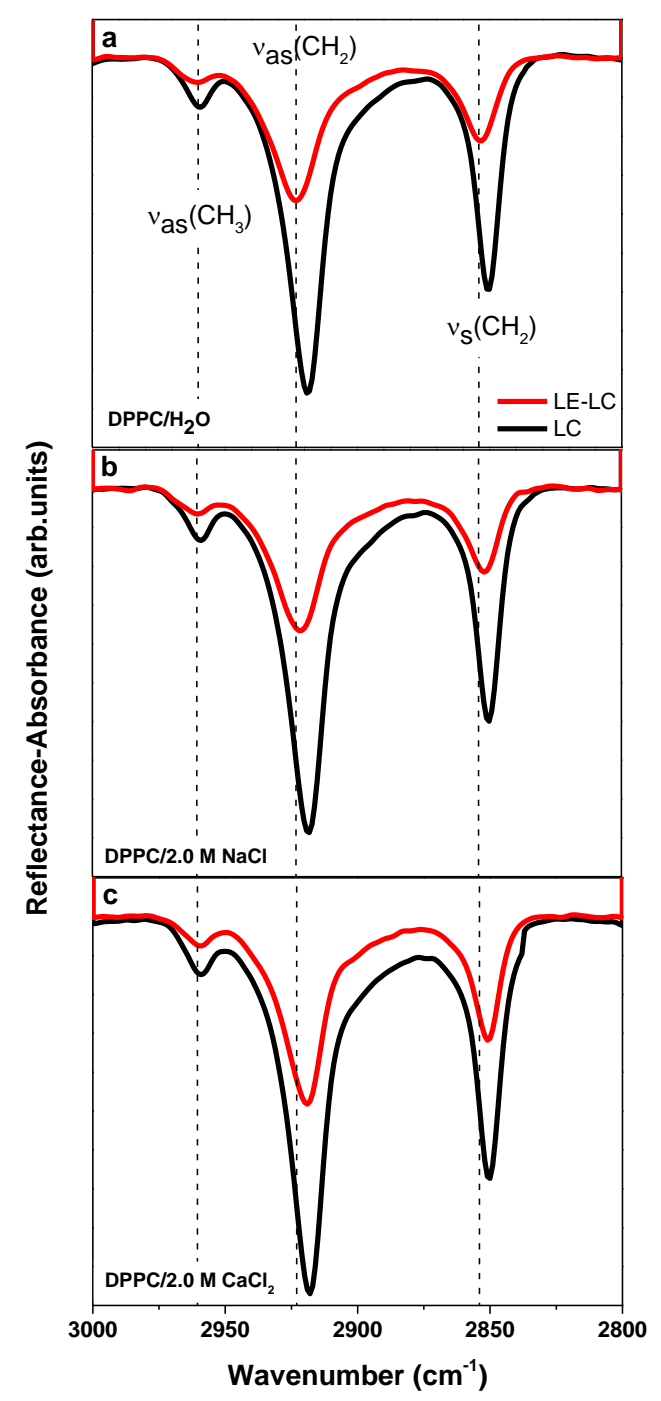

Fig. 7. IRRAS spectra of DPPC monolayers in the LE-LC and LC phases on (a) water and (b) $2.0 \mathrm{M} \mathrm{NaCl}$, and (c) $2.0 \mathrm{M} \mathrm{CaCl}_{2}$ solutions. Vertical lines indicate the peak positions of $\mathrm{CH}$ vibrational modes of DPPC on water in the LE-LC phase. Shifts to lower wavenumbers relative to water indicate that DPPC alkyl chains are more ordered on $\mathrm{NaCl}$ and $\mathrm{CaCl}_{2}$ solutions. 


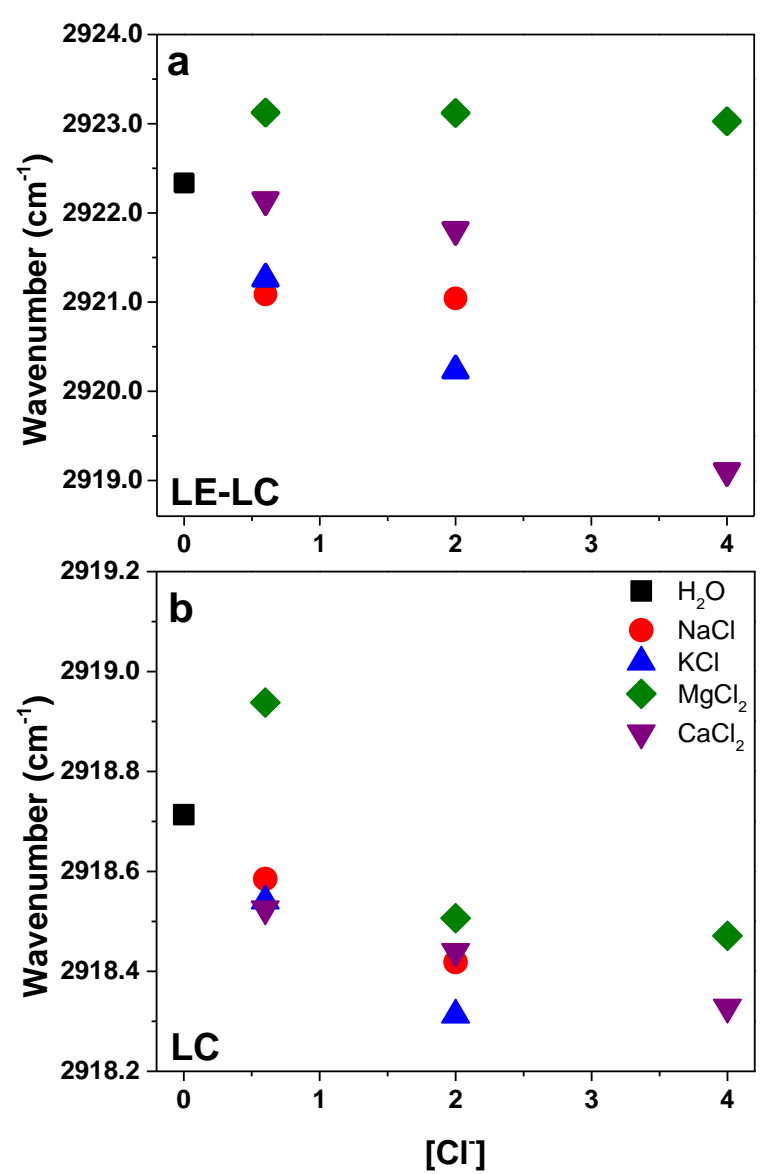

Fig. 8. Peak position of the $\mathrm{CH}_{2}$-as vibrational mode of $\mathrm{DPPC}$ on $\mathrm{NaCl}, \mathrm{KCl}, \mathrm{MgCl}_{2}$, and $\mathrm{CaCl}_{2}$ solutions as function of $\left[\mathrm{Cl}^{-}\right]$in the (a) $\mathrm{LE}-\mathrm{LC}$ phase $(5-11 \mathrm{mN} / \mathrm{m}$ for various solutions) and (b) LC phase (40 mN/m). Wavenumber shifts of this mode correlates with the relative ordering of the alkyl chain. 


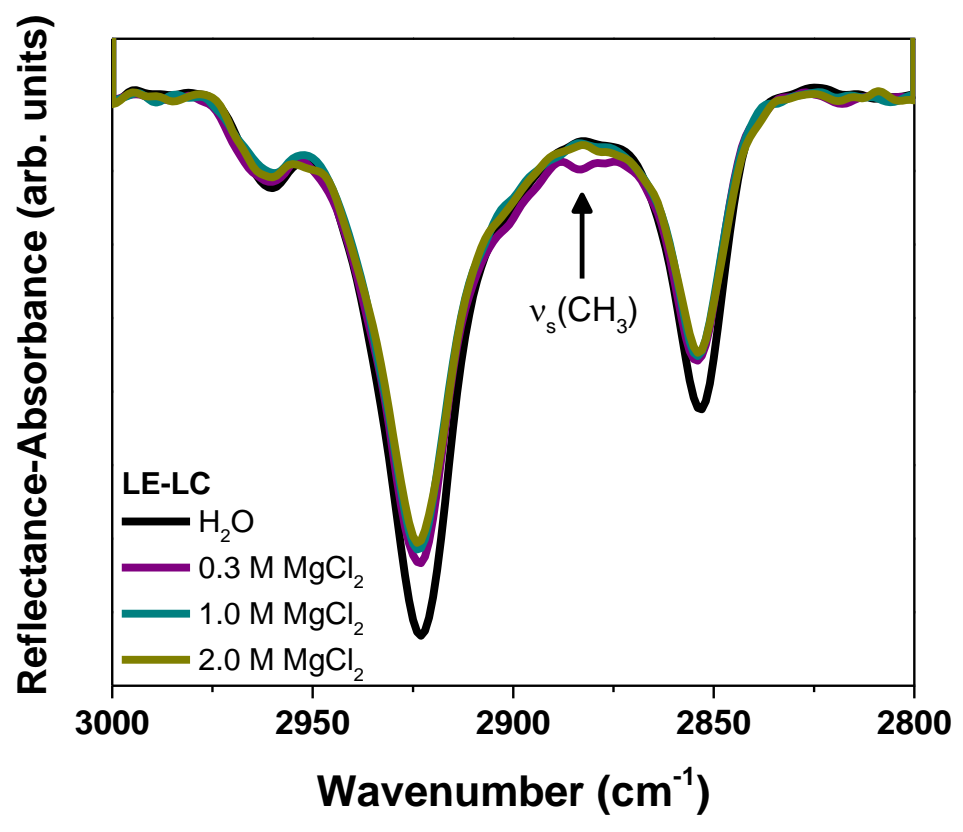

Fig. 9. IRRAS spectra in the $\mathrm{CH}$ region of DPPC monolayers in the LE-LC phase (70 $\AA^{2} /$ molecule) on $\mathrm{MgCl}_{2}$ solutions. A decrease in peak intensity is observed for all major $\mathrm{CH}$ modes with increasing $\mathrm{MgCl}_{2}$ concentration. 


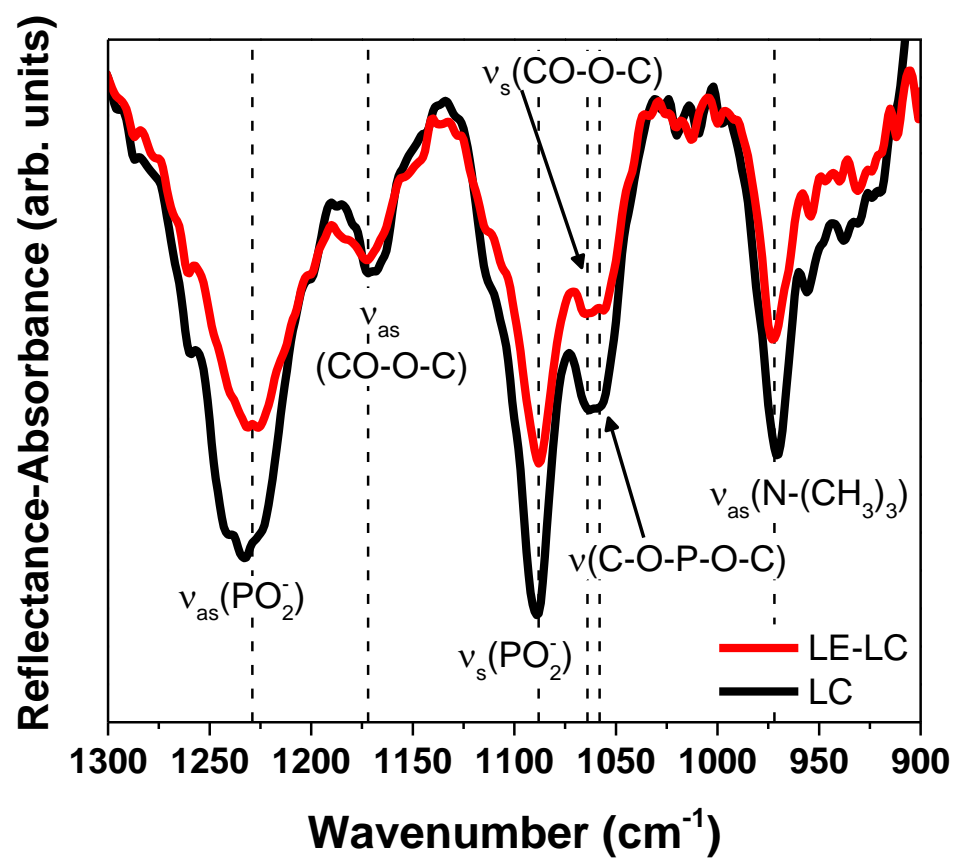

Fig. 10. IRRAS spectra of the phosphate region of DPPC monolayers in the LE-LC and LC phases on a $2.0 \mathrm{M} \mathrm{KCl}$ solution. 


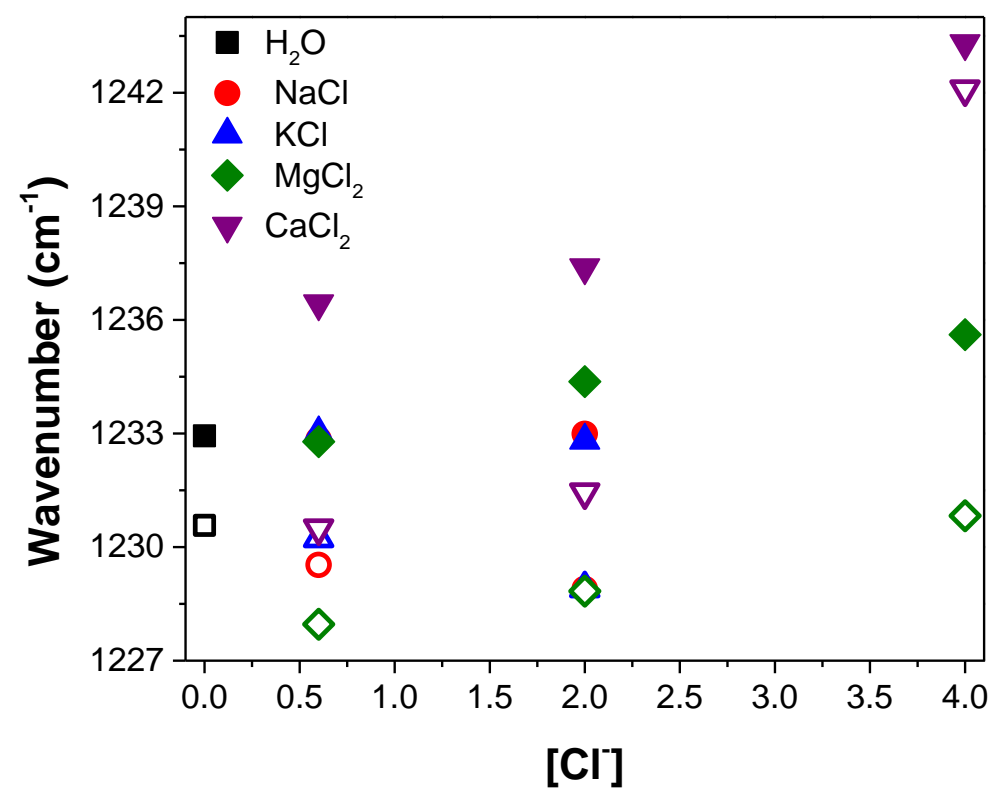

Fig. 11. Peak position of the $\mathrm{PO}_{2}{ }^{-}$-as vibrational mode of DPPC monolayers on $\mathrm{NaCl}$, $\mathrm{KCl}, \mathrm{MgCl}_{2}$, and $\mathrm{CaCl}_{2}$ solutions as a function of $\left[\mathrm{Cl}^{-}\right]$for the $\mathrm{LE}-\mathrm{LC}$ phase (open symbols) and LC phase (filled symbols). Wavenumber shifts of this mode relates to the hydration of the phosphate group. 


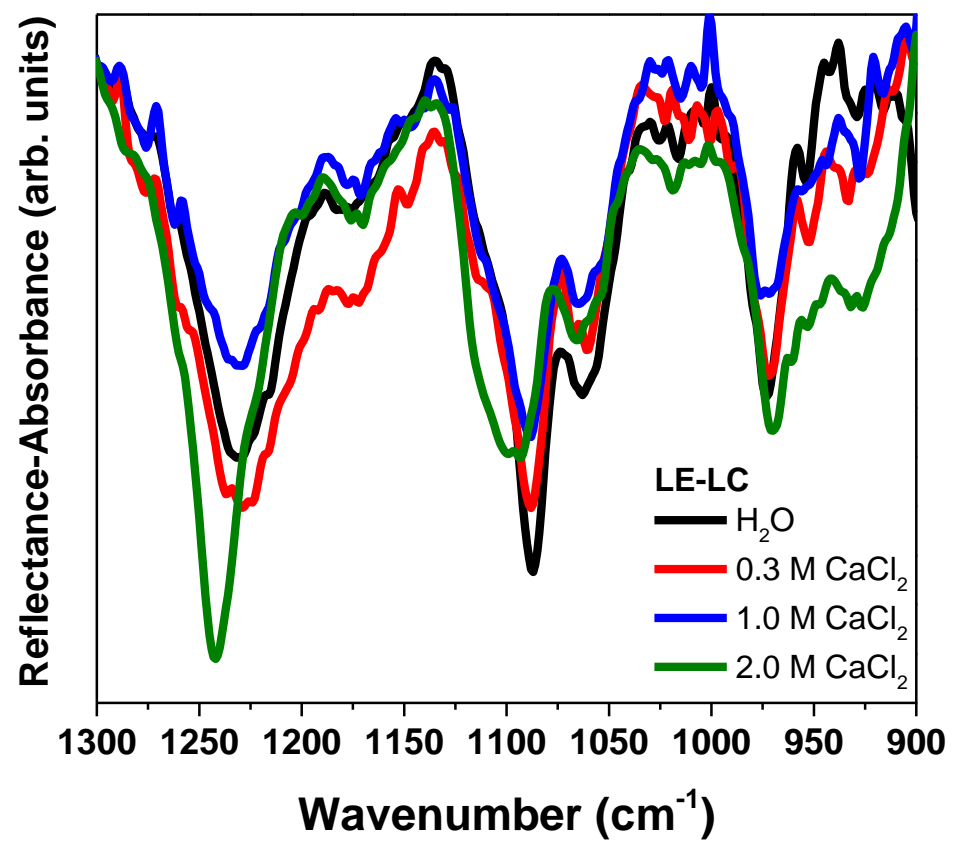

Fig. 12. IRRAS spectra in the phosphate region of DPPC in the LE-LC phase on water and $\mathrm{CaCl}_{2}$ solutions. 


\section{TABLES}

Table 1.

Number density and average domain size of DPPC domains in the LE-LC phase as determined from BAM images of DPPC on various salt solutions. Images were only analyzed for $0.6 \mathrm{M} \mathrm{Cl}^{-}$solution, as distinct domains are not visually discernable at higher concentrations.

\begin{tabular}{lcc}
\hline Subphase & $\begin{array}{c}\text { Number density } \\
\left(\text { domain } \times 10^{-3}\right. \\
\left./ 100 \mu \mathrm{m}^{2}\right)\end{array}$ & $\begin{array}{c}\text { Average domain size } \\
(\mu \mathrm{m})\end{array}$ \\
\hline $\mathrm{H}_{2} \mathrm{O}$ & 81.0 & $31.4 \pm 2.6$ \\
$0.6 \mathrm{M} \mathrm{NaCl}$ & 97.0 & $28.6 \pm 4.3$ \\
$0.6 \mathrm{M} \mathrm{KCl}$ & 130 & $23.8 \pm 3.6$ \\
$0.3 \mathrm{M} \mathrm{MgCl}$ & 227 & $19.2 \pm 2.0$ \\
$0.3 \mathrm{M} \mathrm{CaCl}_{2}$ & 411 & $13.7 \pm 4.6$ \\
\hline
\end{tabular}




\section{Graphical Abstract}

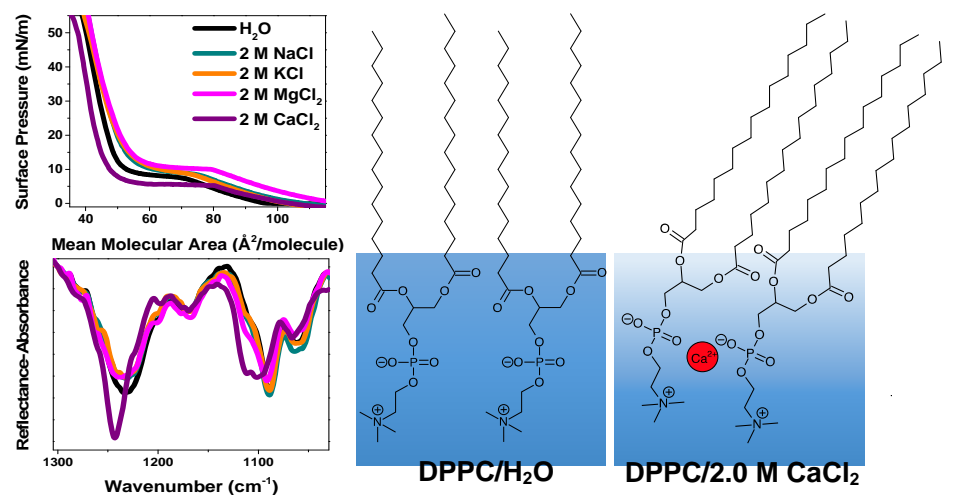

